\title{
Unconditional Aid and Green Growth
}

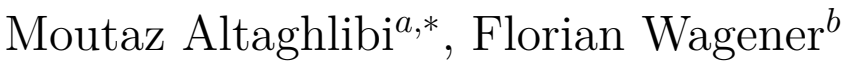

December 15, 2018

\author{
${ }^{a}$ CeNDEF, Amsterdam School of Economics, Universiteit van Amsterdam \\ Paris School of Economics, Université Paris 1 Panthéon-Sorbonne, France \\ * Corresponding author, PO Box 15867, 1001 NJ Amsterdam, The Netherlands; \\ M.Altaghlibi@uva.nl \\ ${ }^{b}$ CeNDEF, Amsterdam School of Economics, Universiteit van Amsterdam, \\ Tinbergen Institute, The Netherlands \\ F.O.O.Wagener@uva.nl
}

\begin{abstract}
Environmentally motivated aid can help developing countries to achieve economic growth while mitigating the impact on emission levels. We argue that the usual practice of giving aid conditionally is not effective, and we therefore study aid that is given unconditionally. Our framework is a differential open-loop Stackelberg game between a fully developed leader country and a developing follower country. The leader chooses the amount of mitigation aid given to the follower, which the follower either consumes or invests in either costly non-polluting capital or cheap high-emission capital. We show that giving aid conditionally is only rarely effective and, if so, is based on a forced intertemporal savings effect. In all other cases it is ineffective at best and counterproductive at worst. Moreover, we find that the leader gives unconditional mitigation aid only when sufficiently rich or when caring sufficiently about environmental quality. If unconditional aid is given in steady state, it decreases the steady state level of high-emission capital and capital investments in the recipient country as well as the global pollution stock, but it has no effect on the levels of non-polluting capital and non-polluting investments. Transitional aid accelerates the economic growth of the follower. Moreover, we find that the increase in growth takes place in the non-polluting sector.
\end{abstract}

Keywords: Strategic transfers, Development aid, Green growth, Conditionality, Open loop Stackelberg equilibrium

JEL codes: H41, Q56, O13 


\section{Introduction}

Through the 2015 Paris Climate Agreement all countries acknowledge the negative impact of climate change to each country regardless of its development level. Growth is historically accompanied with high levels of pollution; as climate change is a global rather than national problem, it is in the global interest to direct the growth path of least developed countries towards building low-emission rather than high-emission industrial capital.

It is generally accepted that the first best solution to the climate change problem is to implement a unique carbon tax among all countries, but the political difficulties are as yet overwhelming. Another solution is that developed countries donate environmentally motivated aid voluntarily: the Paris agreement envisages this mechanism, as each signatory country specifies a 'Nationally Determined Contribution'. The agreement has been criticised precisely because these contributions are voluntary and there is no enforcing mechanism in place.

To investigate this criticism we build a model of environmentally motivated development aid. We find that a fully developed country that has exhausted its domestic abatement possibilities can have an environmental incentive to provide a developing country with mitigation aid, making both countries better off. At present, developed countries have still ample scope for domestic abatement, but as these opportunities become scarcer, the question investigated in this paper will become more relevant.

Generally, a donor country can give aid either unconditionally, or conditional on the recipient country investing in certain kinds of non-polluting capital. Adam and O'Connell (1999) call attention to institutional failures that may prevent aid conditionality to work optimally. In this article we therefore investigate the role of conditionality on aid effectiveness and the conditions under which a donor will give unconditional aid. We use an infinite horizon Ramsey growth model for the developing country, modelling the relation between donor and recipient as a Stackelberg differential game with the donor as leader, and determining the equilibrium amount of aid. We also analyse the effects of this aid on the growth of the recipient country and the direction of the resulting growth.

We find that the donor country gives aid if it is rich or if it values environmental quality highly. In these situations, equilibrium aid programmes extend over an infinite time period, and the giving of aid is weakly time-consistent: the donor country has no incentive to renege on its commitment to give aid. Giving aid Pareto-improves the situation of both countries. The recipient country uses most of the aid to increase consumption, which relieves it from the need to invest strongly in a high-emissions 'brown' industry, and allows it to build up a non-polluting 'green' industry instead. Making aid conditional on investment into green industries is only rarely effective, and then relies on an intertemporal savings effect. In all other situations, it has either no effect, if the conditionality is not binding, or an adverse effect: as the recipient country is prevented to allocate its investments optimally, marginal productivity of green capital is below the unconditional optimal value, while marginal productivity of brown capital is above optimal. This gives the recipient an incentive to increase investment in brown capital. 


\section{Literature}

Our model does postulate a purely environmental motivation of development aid, it recognises explicitly the incentive and the practical possibilities of the recipient country to re-allocated the aid received as it sees fit, and it takes a long-term dynamical perspective. While there are several papers that look at one or two of these aspects, the present paper is the first to combine all three.

\subsection{Aid and development}

Rajan and Subramanian (2008) and Alesina and Dollar (2000) discuss possible incentives for donor countries to give aid: ethical international equity concerns, historical relations, political and strategic reasons, or poverty alleviation and growth promotion in the recipient country. Sometimes the need to secure a global agreement might include transfers between countries. Other motives include strategic environmental concerns, donors caring about global environmental quality. The 2015 Paris Climate Agreement illustrates these motives, as environmentally motivated transfers were an essential aspect of the agreement. $^{1}$

The literature on development aid focuses mainly on identifying the effectiveness of foreign aid on the economic growth of recipient countries. Empirical work has provided conflicting evidence about the effect of development aid on growth. Some studies found that aid has no effect on the growth of recipient countries (Boone (1996), Rajan and Subramanian (2008) and Doucouliagos and Paldam (2008)), others concluded that aid improves economic development Hansen and Tarp (2000) and Mekasha and Tarp (2013)), while Mosley (1986) found a positive effect of aid only on the micro level.

When one country grants aid to another country for a specific purpose, credibility is an issue, as the actions of - typically - the recipient country may deviate from what is initially agreed on after the aid payment has taken place. Conditionality is the typical mechanism to deal with moral hazard situations between recipient and donor countries (Svensson 2000). Using conditionality, donors try to influence policy and to induce reforms in recipient countries; they also try to make sure that the recipient country uses the promised aid flow effectively, at least in terms of the donor's criteria (Azam and Laffont 2003).

There are however numerous problems associated with conditionality: donors are reluctant to enforce sanctions (Svensson 2000); both success and failure of the recipient to satisfy conditions are cited to justify giving more aid (Easterly 2003); new governments are often given a 'clean slate' from aid agencies (Easterly 2003); enforcing conditionality may be in conflict with other goals of the aid agency, cf. Mosley et al. (1995) who quotes an example from the World Bank. Both Svensson (2003) and Mosley et al. (1995) moreover argue that the current working system is biased towards disbursing aid regardless of the reform effort.

\footnotetext{
${ }^{1}$ For other kinds of donor's incentives we refer to Lahiri and Raimondos-Moller (2000).
} 


\section{$2.2 \quad$ Aid and climate}

Under the terms of the 2009 Copenhagen Accord, which were later re-emphasised by the 2015 Paris Climate Agreement, developed countries engaged in providing climate finance up to $\$ 100$ billion per year, starting from 2020 onward, to help developing countries reduce their emissions and adapt to the consequences of climate change (Eyckmans et al. 2016).

As a consequence of these pledges, a theoretical literature on the effectiveness of climatemotivated transfers has emerged. Eyckmans et al. (2016) found, in a two period Stackelberg game, that a large part of the intended effect of transfers dissipates as the follower reallocates its own resources to achieve the balance it prefers. Pittel and Rübbelke (2013) underline the sensitivity of the results on the productivity of mitigation and adaptation technologies. Heuson et al. (2015) show that there are many instruments of climate funding which possibly yield Pareto improvements for donor and recipient countries, and that therefore transfers might induce an implicit cooperation between regions. ${ }^{2}$

A major mitigation instrument is the building of 'green' industries, which "reduce greenhouse gas and air pollutant emissions, without significantly reducing the production and consumption of non-energy goods" (Eyraud et al. 2011). Rozenberg et al. (2014) and Claude et al. (2012) analyse different policies and configurations to induce such a switch towards green capital.

Strategic transfers to induce the private provision of public goods have been investigated using one-shot game theoretical models, starting with Warr (1983), Buchholz and Konrad (1995) and Ihori (1996). The typical result is that if the players have different public good productivity, the less productive agent has an incentive to make unconditional transfers to the more productive agent. Of direct interest to our analysis is Vicary and Sandler (2002), who compared in-cash - unconditional transfers - to technology - conditional - transfers, and find that the former can Pareto-dominate the latter. The conflicting demand of policies for developing countries between policies that improve living conditions and those that address climate change has been noted in many places, see Klein et al. (2005) and Rübbelke (2011) and their references.

\subsection{Our contribution}

In our model, a donor is a developed sovereign country for which greenhouse gas emissions by another sovereign country constitute an externality, and which gives aid in order to induce the developing country to reduce these emissions. We therefore investigate endogenously given aid in a noncooperative differential game framework where the donor, North, is a Stackelberg leader and the recipient, South, a Stackelberg follower.

The failure to achieve a stable global agreement on climate change is the starting point of the paper. Also, it is assumed that each country knows the extent to which its decisions impose costs on itself and on the other country (for informational considerations cf.

\footnotetext{
${ }^{2}$ Bowen et al. (2012) discuss development, climate vulnerability, and adaptation.
} 
Morath 2010). These two assumptions justify the use of a Stackelberg setting. In addition, as aid is a gift, moving sequentially is natural, that is, aid is a unilateral action that can be followed by other unilateral actions.

Several situations featuring environmentally motivated positive levels of unconditional transfers motivated by the global environmental quality have been studied already, see Stranlund (1996), Ono (1998), Ono and Maeda (2002), Vicary and Sandler (2002) and Altemeyer-Bartscher et al. (2010). The role of conditionality on the outcome of such transfers has however not been emphasised.

We show below first that if polluting and non-polluting capital are substitutes, giving aid conditionally on it being employed to invest into green industries is ineffective at best and counterproductive at worst. This is the first central result of our article, and it motivates to consider unconditional aid in the remainder of the investigation. We therefore consider the situation that the leader, motivated by environmental considerations, announces an aid programme where aid is given unconditionally and independently of the actual actions of the recipient follower. This gives the recipient country the choice to use the aid in a way that achieves its best interest. If under these conditions it is optimal for the Leader to give aid, it will be a Pareto-improvement.

In our dynamic Stackelberg approach, the donor country envisages that the optimal response of recipient will use most of the aid for other purposes than the development of green capital, but that the remaining green investments are sufficient to justify the transfer. There is still a credibility problem, though of a different kind: the institutions of the recipient country have to be sufficiently strong to guarantee that aid will not be misallocated. A certain amount of misallocation could be modelled by assuming that a fraction of the aid is 'lost' during the transfer. We have not taken this into account explicitly, but our results are robust to small losses.

In our dynamic approach, there is a second credibility aspect, other than moral hazard, that is related to the credibility of the donor, which has not been mentioned in the static conditionality literature. When an aid programme is announced, the recipient changes its investment policy to use the aid optimally. In our context, this means that capital investments shift towards green industries early on, and even before the start of the aid programme. As these investments are taken to be irreversible, the donor country might have then an incentive to renege on its aid promise. We therefore investigate only those programmes that are weakly time consistent, that is, where the donor country has in no point of time an incentive to renege. Our solution concept is an extension of openloop Stackelberg equilibria, as it is known that these often fail to be time consistent. We extend the game by giving South the option to use a trigger strategy in case North deviates from its originally announced aid programme. Section 6.3 shows that a subset of open-loop Stackelberg equilibria is time consistent under this extension.

Eyckmans et al. (2016), which employs a two-period framework to model mitigation and development transfers, is closest to our approach in spirit: they find that conditionality reduces the effectiveness of transfers as the recipient reallocates resources. In their model, motivation for giving aid is however ethical rather than strategic, and they work with 
very specific functional forms. Unlike them, we do not impose exogenous emission constraints, but model damage flows from global pollution to provide endogenous incentives for mitigation. We follow them by not considering global welfare: each country takes only its own welfare into account when taking its decisions. Our model also links the green investments literature and climate finance literature; to the best of our knowledge only Claude et al. (2012) study a similar link.

The next section presents the model and the dynamic optimisation problem of each player. Then we give theoretical results about the steady state of the resulting Stackelberg equilibrium dynamics. To analyse the transient dynamics, numerical techniques are necessary. We discuss their methodology before turning to the results and the conclusions.

\section{The model}

\subsection{The aid game}

In our framework, all countries care about the consumption and the quality of the environment of their citizens, which translates to an intertemporal trade-off between short term consumption benefits and long term environmental costs. A country can grow by either investing in costly, non-polluting, 'green' capital or cheap, high-emission, 'brown' capital. Brown capital contributes through emissions to degradation of the global environmental quality; the latter is a public good affecting both developed and developing countries alike. Developing countries are assumed to have credit constraints, as their high probability of defaulting on debts restrict their access to financial markets. We consider the situation, which in practice has not been realised yet, that the developed country has exhausted all domestic abatement possibilities. To avoid future environmental degradation it may be motivated to give aid to developing countries, helping these countries to achieve economic growth with minimal effect on the environment. Since the adverse effects of climate change are felt over a long time, it is natural to study this problem in an infinite horizon framework.

We study a Stackelberg differential game between two countries: The leader, which will be called 'North', is a developed country; the follower, 'South', a developing country. North's decision variable is the amount of aid that it gives to South; this lessens North's consumption budget. North is assumed to be unable to observe how South uses the aid it receives; aid therefore automatically becomes unconditional. South's decision is how to allocate its output and the aid it receives from North between consuming, investing in brown capital, or investing in green capital.

We solve for open-loop Stackelberg equilibria: this means that North's aid schedule is fixed at the initial time, and that the amount of aid given depends merely on the date, but not on any other variable. A closed-loop approach, where the amount of aid would depend on the current state variables, would involve similar problems as discussed above in the context of conditionality: South would need strong institutions to measure and report the capital stocks correctly, and in practice the lowering of aid as a consequence 
of an adverse stock evolution might easily give rise to political tensions. The open-loop approach avoids this, as the aid schedule is fixed and known beforehand. Of course, for an announced aid schedule to be credible, it needs to be time consistent. This issue will be addressed in Section 6.3.

\subsection{South's decision problem}

We begin by describing South's decision problem, given North's aid schedule $a_{t}$.

\subsubsection{Consumption}

South's citizens are assumed to be identical and to be represented by an infinitely lived representative agent, who gains utility $u\left(c_{t}\right)$ from consuming $c_{t}$ of a generic good and dis-utility $D\left(E_{t}\right)$ from environmental degradation represented by a damage function of a global pollution stock $E_{t}$. The discounted intertemporal welfare of South's representative consumer can be written as:

$$
W=\int_{0}^{\infty} e^{-\rho t}\left(u\left(c_{t}\right)-D\left(E_{t}\right)\right) d t .
$$

Here $\rho$ denotes the time preference rate. The utility function $u$ is assumed to have positive first and negative second derivative, hence it is increasing and concave, while the damage function $D$ is assumed to have positive first and second derivatives, which implies that it is increasing and convex. Furthermore, we assume marginal utility has unbounded steepness at zero.

\subsubsection{Production}

Output comes from production processes using brown capital $K_{b, t}$, green capital $K_{g, t}$ and labour $L_{t}$ as factors of production. In the present article we fix labour supply and focus on physical capital as variable inputs for production. We expect that including a growing labour supply will necessitate a higher capital growth rate to meet the demographical changes, which in turn should give South an incentive to use aid more to increase growth. This might increase emissions and therefore lessen the incentive for North to give aid. However, in view of the present complexity of the analysis, we leave the inclusion of labour as a variable input for future research. South's total output is therefore a function of the stocks of brown and green capital

$$
Y_{t}=F\left(K_{b, t}, K_{g, t}\right)
$$

The function $F$ is assumed to be separately increasing in each argument and jointly concave in both arguments. Moreover, we assume throughout that an increase of one factor increases the marginal productivity of the other. 
In much of the analysis below, we shall think of capital stocks as energy plants. As energy is in general equally productive regardless of its source, we assume that production is separable in the two inputs. In that situation, the production function is the sum of the two production functions $F_{b}$ and $F_{g}$, for brown and green capital respectively

$$
F\left(K_{b, t}, K_{g, t}\right)=F_{b}\left(K_{b, t}\right)+F_{g}\left(K_{g, t}\right)
$$

The functions $F_{b}$ and $F_{g}$ are then both increasing and concave.

South's invests, per unit time, $I_{b, t}$ in brown capital and $I_{g, t}$ in green capital. The investment costs $C_{i}\left(I_{i, t}\right)$ are assumed to be increasing from 0 and convex. Both types of investment are assumed to be irreversible: once an investment has been made, the resulting capital cannot be transformed to a different type of capital. Moreover, we shall assume that brown investments are cheaper than green investments. In most of the analysis, we shall assume investment costs to be quadratic:

$$
C_{i}\left(I_{i, t}\right)=\frac{\beta_{i}}{2} I_{i, t}^{2}, \quad i \in\{b, g\}
$$

where $\beta_{i}>0$ is the rate of increase of the marginal investment costs. The assumption that brown investments are cheaper than green investments then translates to $\beta_{b} \leq \beta_{g}$. The price of the generic good is normalised to 1 .

Along with its output from the production process, South may receive aid from North. At each point of time South allocates its output and the aid it receives between consuming, investing in green capital and investing in brown capital, taking into account its budget constraint

$$
F\left(K_{b, t}, K_{g, t}\right)+a_{t}=c_{t}+C_{b}\left(I_{b, t}\right)+C_{g}\left(I_{g, t}\right)
$$

We model the situation that part of North's aid is given conditionally on it being spent on green investments. If $0 \leq \varepsilon \leq 1$ is the fraction of aid to be spent in this way, South faces the restriction that

$$
C_{g}\left(I_{g, t}\right) \geq \varepsilon a_{t}
$$

Capital dynamics are assumed to take the same form for both kinds of capital

$$
\dot{K}_{i, t}=I_{i, t}-\delta K_{i, t}, \quad K_{i, 0} \quad \text { given, } \quad i \in\{b, g\} .
$$

Each type of capital increases with new investments and depreciates with a uniform capital depreciation rate $\delta>0$.

Production processes involving brown capital emit greenhouse gases, which accumulate in the atmosphere. Pollution is therefore transboundary, affecting consumers in both countries. The dynamics of the pollution stock is given as:

$$
\dot{E}_{t}=\alpha K_{b, t}-\vartheta E_{t}, \quad E_{0} \quad \text { given. }
$$


That is, pollution emissions are proportional to the amount of installed brown capital, with an emission intensity $\alpha$; without emissions, the pollution stock decreases at the natural decay (absorption) rate $\vartheta$.

South maximises its intertemporal welfare, taking into account capital and pollution dynamics. That is, South maximises the objective functional (1) subject to the budget constraint (5), the investment constraint (6) and the dynamic constraints (7) and (8). The first order conditions for this optimisation problem are given in appendix A.1.

\subsection{North}

\subsubsection{Consumption}

North's citizens are, analogously to South's, represented by an infinitely lived agent who gains utility from consumption and dis-utility from environmental degradation. We use a superscript $n$ to denote North's variables. The discounted intertemporal welfare of North's representative agent is

$$
W^{n}=\int_{0}^{\infty} e^{-\rho t}\left(u^{n}\left(c_{t}^{n}\right)-D^{n}\left(E_{t}\right)\right) d t
$$

where $u^{n}$ and $D^{n}$ are assumed to be, respectively, increasing and concave and increasing and convex. Again we assume that the steepness of $u^{n}$ is unbounded at zero consumption.

In the next section, we consider the situation that North gives aid conditionally on a fraction being used for green investments, with the intention to reduce the global pollution stock. We find that such a policy is typically either ineffective, if the condition is not binding, or counterproductive if it is. We therefore assume in the remainder of the paper that aid is given unconditionally.

\subsubsection{Production}

We simplify North's problem as much as possible in order to focus on analysing the aid effects on South and to make the model more tractable. Baldwin et al. (2016) show that the expectation of a carbon tax that increases over time reduces irreversible investments in polluting capital, thus no or little new investments in this kind of capital are expected to take place in the developed world. This means, for our framework, that North's brown capital only depreciates over time, which is equivalent to setting the initial pollution stock at the beginning of the time horizon to a higher level. Furthermore, we are interested in the case where North has already exhausted all domestic mitigation opportunities; that is, its mitigation productivity is zero (cf. Buchholz and Konrad 1995, Ihori 1996) and South is the only one that can reduce global emissions. Therefore, we simplify North's problem by assuming that North is a fully developed country having only green capital at the steady state level. This level is assumed to be at least equal to the sum of the steady state levels of South's brown and green capitals. North's production processes use 
only green capital and produce the output $Y^{n}$, which is net of depreciation costs. North has to decide at each point of time how to allocate its output between consumption and unconditional aid to South. Its budget constraint takes the form:

$$
Y^{n}=c_{t}^{n}+a_{t}
$$

Moreover, North can choose whether or not to give aid to South, but it cannot force South to pay aid back; hence there is a positivity constraint on aid:

$$
a_{t} \geq 0
$$

Finally, we restrict the analysis of North's problem to the unconditional case $\varepsilon=0$.

\subsubsection{North's dynamic optimisation problem}

Since we have a Stackelberg open-loop game, North will choose the amount of aid that maximizes the intertemporal welfare of its representative consumer, subject to its budget constraint (10), the aid positivity constraint (11), as well as South's first order conditions (23)-(29).

For North's problem, we use the explicit functional forms (4) for the investment costs and we assume separable production (3). The first order conditions of North's optimisation problem are derived in appendix B.1.

\section{$4 \quad$ Steady state analysis}

In this section we investigate the steady state effects of imposing conditionality requirements on the use of aid, we present a comparative statics analysis for the steady state levels of South's capital and consumption, and we give sufficient conditions for a positive aid flow to occur at steady state.

\subsection{South's decision problem}

To analyse the steady state levels of South's capital and consumption in the full model, it is sufficient to study a rest point of the evolution equations (7) - (8) and (24) - (26) of South's states and shadow prices. The solution procedure for the steady state can be found in Appendix A.2.

The steady state level of pollution is proportional to the steady state level of brown capital

$$
E=\frac{\alpha}{\vartheta} K_{b}
$$


The steady state levels of green capital, brown capital and consumption are simultaneously determined by the equations

$$
\begin{aligned}
F_{K_{g}}^{\prime}\left(K_{b}, K_{g}\right) & =(\rho+\delta) C_{g}^{\prime}\left(\delta K_{g}\right)-(\rho+\delta) \frac{C_{g}^{\prime}\left(\delta K_{g}\right)}{u^{\prime}(c)} \zeta, \\
F_{K_{b}}^{\prime}\left(K_{b}, K_{g}\right) & =(\rho+\delta) C_{b}^{\prime}\left(\delta K_{b}\right)+\frac{\alpha}{\rho+\vartheta} \frac{D^{\prime}\left(\frac{\alpha}{\vartheta} K_{b}\right)}{u^{\prime}(c)}, \\
c & =F\left(K_{b}, K_{g}\right)+a-C_{b}\left(\delta K_{b}\right)-C_{g}\left(\delta K_{g}\right),
\end{aligned}
$$

together with the complementary slackness condition

$$
0=\zeta\left(C_{g}\left(\delta K_{g}\right)-\varepsilon a\right)
$$

The multiplier $\zeta$ associated with the conditionality restriction (6) indicates the tightness of the restriction, as it is proportional to the excess of marginal green investment costs over marginal discounted green investment benefits.

\subsubsection{Binding investment requirement}

We first investigate the situation that the investment requirement is binding. The question of interest here is whether North, by imposing the requirement that part of the aid has to be invested into green capital, achieves its aim of reducing South's emissions.

Clearly, conditionality will have no effect if South's optimal green investment level exceeds the part of the aid budget earmarked for green investment.

Theorem 1. There is a critical lower bound $\zeta_{*}$ on the tightness $\zeta$ of the conditionality restriction, such that if $\zeta$ exceeds this lower bound then South's consumption decreases and steady state emissions increase as the level of conditionality $\varepsilon$ increases.

Moreover, the lower bound tends to 0 as the time preference rate $\rho$ tends to 0.

To understand this result, assume that the investment restriction is binding, that is, assume $C_{g}\left(\delta K_{g}\right)=\varepsilon a$. Substituting this into the budget equation (15) and differentiating with respect to $\varepsilon$ yields

$$
\frac{\partial c}{\partial \varepsilon}=a\left(\frac{F_{K_{g}}^{\prime}}{\delta C_{g}^{\prime}}-1\right)+\left(F_{K_{b}}^{\prime}-\delta C_{b}^{\prime}\right) \frac{\partial K_{b}}{\partial \varepsilon} .
$$

The ratios $F_{K_{i}}^{\prime} / C_{i}^{\prime}$ can for $i \in\{b, g\}$ be rewritten using (13) and (14), yielding

$$
\frac{\partial c}{\partial \varepsilon}=\frac{\rho}{\delta} a\left(1-\frac{\zeta}{u^{\prime}}\right)+\frac{\zeta}{u^{\prime}} a+\left(\rho C_{b}^{\prime}+\frac{\alpha}{\rho+\vartheta} \frac{D^{\prime}}{u^{\prime}}\right) \frac{\partial K_{b}}{\partial \varepsilon} .
$$

The first term is an intertemporal forced savings effect. When constrained to invest into green capital, South is shifting consumption from the present into the future. If $\zeta \geq 0$ is small, it may thereby heighten steady state consumption. The second term is the 
decrease of steady state consumption as South is constrained to invest sub-optimally in green capital. The final term represents the impact of the change of the brown capital level on steady state consumption.

By differentiating (14) with respect to $\varepsilon$, we obtain a second relation between $\frac{\partial c}{\partial \varepsilon}$ and $\frac{\partial K_{b}}{\partial \varepsilon}$, namely

$$
(\ldots) \frac{\partial K_{b}}{\partial \varepsilon}=F_{K_{b} K_{g}}^{\prime \prime} \frac{\partial K_{g}}{\partial \varepsilon}-\frac{\alpha}{\rho+\vartheta} \frac{\left(-u^{\prime \prime}\right) D^{\prime}}{u^{\prime 2}} \frac{\partial c}{\partial \varepsilon},
$$

where the factor between brackets on the left hand side is positive. The first term on the right hand side is positive as well: it models the effect that brown capital will be used more if the green capital level increases, as the two kinds of capital are co-productive. The second term on the right shows the environmental effect: if South's steady state consumption decreases, this lowers South's effective concern for the environment and hence forms an inducement for South to increase the steady state level of brown capital. Substituting the expression for $\frac{\partial c}{\partial \varepsilon}$ of (18) into (19) yields finally an expression of the form

$$
(\ldots) \frac{\partial K_{b}}{\partial \varepsilon}=F_{K_{b} K_{g}}^{\prime \prime} \frac{\partial K_{g}}{\partial \varepsilon}+\frac{\alpha}{(\rho+\vartheta) \delta} \frac{\left(-u^{\prime \prime}\right) D^{\prime}}{u^{\prime 2}}\left(\frac{(\rho+\delta) \zeta}{u^{\prime}}-\rho\right) a,
$$

where the factor between brackets on the left hand side is again positive. We conclude that apart from the forced saving effect, the brown capital level, and its implied emissions, increases as the level of conditionality increases, as South is forced to invest into green capital that has lower than optimal marginal productivity.

This is the first main result of our investigation: aid conditionality that is imposed with the intention to reduce global pollution has only a small window of possible effectiveness, that moreover depends on the time discount rate. Outside that window it is ineffective at best and counterproductive at worst.

\subsubsection{Non-binding investment requirements}

In the remainder of the article, we therefore consider the situation that North imposes no investment requirements, that is, $\varepsilon=0$. We also restrict to the situation that the production function is separable (3), as in the case of production of electricity with either green or brown technology. From the assumptions that $\beta_{g} \geq \beta_{b}$ and that brown and green capital have the same productivity, it follows that the steady state level of brown capital with no pollution is at least equal to the steady state level of green capital if either $\alpha=0$ or $D^{\prime}(E) \equiv 0$. This is natural, as green investments are more expensive than brown ones.

The next result we show is the imperviousness of the steady state level of green capital to aid, while the steady state level of brown capital decreases if aid increases. The underlying mechanism is best understood by considering both kinds of capital separately; that is, from (5) we write consumption as $c=F(K)-C(K)+Y_{\text {other, }}$, where $F(K)-C(K)$ is net income from capital $K$, which is subsequently taken equal to green and brown capital, and $Y_{\text {other }}$ the income from the other kind of capital and from aid. 
If $K$ is green capital, steady state welfare depends only on utility from consumption, and the optimal steady state level is that value of $K$ which maximises production. In particular, it is independent of the additional income $Y_{\text {other }}$.

However, if $K$ is brown capital, welfare depends on both utility from consumption and the adverse direct welfare effects brought about by pollution, that is, $W=u(c)-D(K)$. The optimal level of brown capital satisfies $W^{\prime}(K)=0$, which can be written as

$$
0=F^{\prime}(K)-C^{\prime}(K)-\frac{D^{\prime}(K)}{u^{\prime}(c)} .
$$

As marginal disutility $D^{\prime}(K)$ from pollution is positive, $K$ is optimal at a level for which the net marginal productivity $F^{\prime}(K)-C^{\prime}(K)$ is positive as well. But then an increase in $Y_{\text {other }}$, for instance by foreign aid, will lower the marginal utility of consumption, increase the net marginal productivity and hence lower the optimal value of polluting capital.

This simple argument also shows that foreign aid is ineffective if pollution only affects the production function, for then aid would not change the optimal capital level.

Equations (14) and (15) readily furnish information about the effects of parameter changes on the steady state levels $c$ and $K_{b}$ of consumption and brown capital. We begin with the effect of an increase in the aid flow $a$.

Theorem 2. If aid is unconditional and the aid flow a rises, then the steady state level $K_{b}$ of brown capital falls, the steady state consumption level c rises, while the steady state level $K_{g}$ of green capital is unaffected.

Consequently, the steady state levels $I_{b}$ of brown investment and $E$ of the pollution stock fall as well, whereas green investments $I_{g}$ are also unaffected.

Finally, South's total welfare rises.

This theorem is proved in Appendix A.5. The underlying mechanism is the same as in the simple static case described above.

The next result investigates the effects of changing the investment cost parameters $\beta_{g}$ and $\beta_{b}$ and the capital depreciation rate $\delta$.

Theorem 3. Assume that $C_{i}\left(I_{i}\right)=\left(\beta_{i} / 2\right) I_{i}^{2}$, for $i \in\{b, g\}$. If the cost parameter $\beta_{g}$ of green investments falls, the consumption level $c$ and the level of green capital $K_{g}$ rise, while the level $K_{b}$ of brown capital falls.

If the cost parameter $\beta_{b}$ of brown investments falls, the consumption level rises, while the green capital level is unaffected.

If the capital depreciation rate $\delta$ falls, the green capital level and the consumption level rise.

Finally, for small positive values of the emission intensity $\alpha$, the brown capital level rises if either the cost of brown investments or the capital depreciation rate fall. 
Again, the proof of this theorem can be found in Appendix A.5. The result conforms fully to economic intuition.

Finally, we have a result on parameters affecting the pollution stock. Again the results for the brown capital stock are intuitive, and the behaviour of the green capital stock is explained by the mechanism above.

Theorem 4. Assume that $D(E)=(\eta / 2) E^{2}$. If either the natural decay rate $\vartheta$ falls, the emission intensity $\alpha$ rises, or the weight $\eta$ of environmental quality rises, then both the consumption level $c$ and the brown capital level $K_{b}$ fall. The green capital level $K_{g}$ is unaffected.

Moreover, for small positive values of the emission intensity $\alpha$, the pollution level rises with increasing values of $\alpha$, while it falls with increasing values of the natural decay rate $\vartheta$.

This theorem is proved in Appendix A.5 excepting the last statement, which we shall discuss now.

The effect on the global steady state pollution depends on the elasticity of brown capital at steady state with respect to emission intensity, for

$$
\frac{\partial E}{\partial \alpha}=\frac{K_{b}}{\vartheta}\left(\frac{\alpha}{K_{b}} \frac{\partial K_{b}}{\partial \alpha}+1\right) .
$$

The elasticity $\epsilon_{\alpha}=\frac{\alpha}{K_{b}} \frac{\partial K_{b}}{\partial \alpha}$ is negative, therefore the effect of $\alpha$ on $E$ is positive if and only if $\epsilon_{\alpha}>-1$. Clearly this elasticity is 0 if $\alpha=0$, yielding that $E$ rises with $\alpha$ for small values of $\alpha$.

The dependence of the steady state level of pollution on the natural decay rate can be written as

$$
\frac{\partial E}{\partial \vartheta}=\frac{\alpha}{\vartheta^{2}} K_{b}\left(\frac{\vartheta}{K_{b}} \frac{\partial K_{b}}{\partial \vartheta}-1\right)
$$

the effect of $\vartheta$ on $E$ is positive if and only if the elasticity $\epsilon_{\vartheta}=\frac{\vartheta}{K_{b}} \frac{\partial K_{b}}{\partial \vartheta}>1$. If the emission intensity $\alpha$ is zero, industrial production does not affect the pollution level. Conversely the natural decay rate cannot affect the steady state level of brown capital: this results in the fact that $\partial K_{b} / \partial \vartheta=0$, and hence that $\epsilon_{\vartheta}=0$ if $\alpha=0$. By continuity, for small but positive values of $\alpha$, we have that $\epsilon_{\vartheta}$ is close to zero, which results in the steady state pollution level decreasing as $\vartheta$ increases.

\subsection{North's decision problem}

We turn to the question under which conditions North will give aid in steady state. Note that $\xi_{t}$ is North's shortfall of net marginal welfare benefits from aid; as long as 
this quantity is positive, it is not in North's interest to give aid. In Appendix B.2, the following relation is derived for its steady state value, see (64):

$$
\begin{aligned}
\xi=\left(u^{n}\right)^{\prime}\left(Y^{n}-a\right) & -u^{\prime}(c) \frac{\frac{\alpha}{\rho+\vartheta}\left(D^{n}\right)^{\prime}(E)}{\frac{\alpha}{\rho+\vartheta} D^{\prime}(E)+\frac{u^{\prime}(c)^{2}}{-u^{\prime \prime}(c)} \frac{(\rho+\delta) \delta \beta_{b}-F_{b}^{\prime \prime}\left(K_{b}\right)+\frac{\alpha^{2}}{(\rho+\vartheta) \vartheta} \frac{D^{\prime \prime}(E)}{u^{\prime}(c)}}{\rho \delta \beta_{b} K_{b}+\frac{\alpha}{\rho+\vartheta} \frac{D^{\prime}(E)}{u^{\prime}(c)}}},
\end{aligned}
$$

The first term on the right hand side represents the marginal welfare cost of giving aid to North, whereas the second represents the welfare benefits of giving aid. For the latter term to be nonzero, it is necessary that $\alpha>0$ - brown capital generates pollution and $\left(D^{n}\right)^{\prime}(E)>0$ - North suffers from pollution.

Note that it is not necessary that South suffers from pollution. That is, even if $D(E)=0$ for all $E$, it may be worthwhile for North to give aid, in order that South does not have to build its polluting industry to its full non-aid level.

On the other hand, set $D(E)=(\eta / 2) E^{2}$ and $D^{n}(E)=\left(\eta^{n} / 2\right) E^{2}$. Then (21) implies the inequality

$$
\xi \geq\left(u^{n}\right)^{\prime}\left(Y^{n}-a\right)-\frac{u^{\prime}(c)}{D^{\prime}(E)}\left(D^{n}\right)^{\prime}(E)=u^{\prime}(c)\left(\frac{\left(u^{n}\right)^{\prime}\left(c^{n}\right)}{u^{\prime}(c)}-\frac{\eta^{n}}{\eta}\right) .
$$

If $\eta$ increases, then according to theorem 4 emissions and brown capital decrease. It follows from (14) that then the ratio $D^{\prime}(E) / u^{\prime}(c)$ increases. Consequently the right hand side of this inequality increases. There will be a critical value $\eta_{*}$ such that for $\eta \geq \eta_{*}$, the right hand side is positive and North will not be giving aid in steady state. The next result summarises this discussion and constitutes our second main theoretical result.

Theorem 5. Set $D^{n}(E)=\left(\eta^{n} / 2\right) E^{2}$ and assume that $\eta^{n}>0$. Then the following are true in steady state.

a. The welfare benefits of North's giving aid are positive.

b. If North is sufficiently rich ( $Y^{n}$ is large) or sufficiently concerned about the environment ( $\eta^{n}$ is large), it will give aid. This is even the case if South does not suffers damages from global pollution.

c. If the ratio of North's to South's marginal utilities exceeds the ratio of North's to South's marginal damages, then North does not give aid. In particular, if South is sufficiently concerned about pollution, North does not give aid.

To conclude, unconditional aid decreases the steady state level brown capital, brown investments, and the stock of global pollution, it increases South's consumption and total welfare, and it has no effect on the steady state level of green capital or green investments. Moreover, if North can afford it or is sufficiently concerned about the environment, it is in North's interest to provide South with mitigation aid. This effectively amounts to North buying off the need to build brown capital and by that buying off the resulting pollution. 


\section{Methodology}

Next to the steady state, we are also interested in the growth path towards it, and its dependence on the parameter change, its 'comparative dynamics'. If there are to be any aid transfers, we expect the bulk to be effected during the growth phase of South, which is, by definition, not in steady state. Solving the model analytically is however beyond our capabilities; we have therefore resorted to numerical simulations.

This section discusses the numerical methods with which the Stackelberg open loop equilibria of the dynamic game are determined and motivates the calibration of the model parameters.

\subsection{Numerical Solution}

Section 3.2 formulated the necessary conditions of South's decision problem in the form of a boundary value problem over an infinite time interval, involving six nonlinear differential equations, together with initial and terminal conditions; North's boundary value problem features twelve nonlinear differential equations. We adapt a numerical approach taken from Grass (2012).

In general, boundary value problems deriving from infinite horizon optimisation problems with $m$ state variables are characterised by the following elements: a $2 m$-dimensional system of differential equations, determining solution paths $z_{t}=\left(x_{t}, y_{t}\right) \in \mathbb{R}^{m} \times \mathbb{R}^{m}$, where $x_{t}$ is the state evolution and $y_{t}$ the co-state evolution; a specification of the initial states $x_{0}$, which yields $m$ initial conditions; a specification of $m$ asymptotic transversality conditions, which are typically satisfied by a solution of the system that tends to steady state values $\hat{z}=(\hat{x}, \hat{y})$.

In order to solve for such solution paths numerically, we approximate the asymptotic conditions by conditions that hold for a large, but finite, time T. Following Grass (2012), we impose the following 'asymptotic transversality condition'

$$
M^{T}\left(\begin{array}{l}
x_{T}-\hat{x} \\
y_{T}-\hat{y}
\end{array}\right)=0 ;
$$

here the columns of the matrix $M$ form a basis spanning the orthogonal complement to the stable eigenspace at steady state, and $M^{T}$ denotes the transpose of $M$. The geometrical content of $(22)$ is that the vector $z_{T}=\left(x_{T}, y_{T}\right)$ is contained in the stable eigenspace of the steady state $\hat{z}$, and therefore approximately in the stable manifold of the steady state. Note that (22) consists of $m$ scalar conditions on the $2 m$-dimensional vector $z_{T}$. The $2 m$ differential equations, together with $m$ initial state conditions and $m$ asymptotic transversality condition then form a boundary value problem over the finite time interval $[0, T]$. As $T \rightarrow \infty$, the solution curves of the approximate problem tend uniformly to solution curves of the original problem.

Specifically, South's boundary value problem consists of the state equations $(7)-(8)$ and equations $(24)-(26)$ for South's marginal valuations of the states, together with 
initial conditions at $t=0$ for the three states $K_{b, t}, K_{g, t}$, and $E_{t}$, and the transversality conditions (29). The initial conditions are South's initial capital stocks $K_{b, 0}$ and $K_{g, 0}$, and the initial pollution stock $E_{0}$.

North's problem involves twelve differential equations: South's equations (7) - (8), (24) - (26) and the equations for North's marginal valuations of the states and of South's marginal valuations (49) - (54), as well as twelve boundary conditions. The first six of these are equal to South's boundary conditions, the initial conditions for the states and the transversality conditions (29) for the co-states. In addition, boundary conditions on North's co-states are furnished by the transversality conditions (56) and the initial conditions (57).

\subsection{Functional forms}

We assume that both South's and North's representative agent have a constant intertemporal elasticity of substitution utility

$$
u(c)=u^{n}(c)=\frac{c^{1-\sigma}}{1-\sigma} .
$$

In computations, we take $\sigma=0.5$, which yields an intertemporal elasticity of substitution of 2. We take Cobb-Douglas production functions with the factor labour taken constant; we assume moreover that green and brown technology are equally productive, yielding

$$
F_{b}(K)=F_{g}(K)=\frac{\Omega}{1-\gamma} K^{1-\gamma} \quad \text { for all } K \text {. }
$$

In computations we set $\Omega=0.6$ and $\gamma=0.75$.

The damage functions are assumed to be quadratic:

$$
D(E)=\frac{\eta}{2} E^{2}, \quad D^{n}(E)=\frac{\eta^{n}}{2} E^{2}, \quad \text { for all } E .
$$

The parameters $\eta$ and $\eta^{n}$ govern the weight of the environmental quality in the welfare of each country.

\subsection{Calibration}

To calibrate the parameters in our model, we take a wind energy plant as a model for green industrial capital, and a traditional coal or gas energy plant as a model for brown capital.

The relative cost $\beta_{g} / \beta_{b}$ of green investments with respect to brown is calibrated as the ratio between investment costs of a wind plant to that of a coal/gas plant. Salvadore and Keppler (2010) estimate that the specific overnight construction costs of most coal-fired plants range between 1000 and $1500 \mathrm{USD} / \mathrm{kWe}$, while those of a gas-fired plants range between 400 and $800 \mathrm{USD} / \mathrm{kWe}$. In contrast, for nuclear and wind generating technologies 
overnight construction costs range between 1000 and 2000 USD/kWe. Accordingly, we calibrate $\beta_{g} / \beta_{b}$ to range between 1 and 2.5.

For the emission intensity $\alpha$ of brown capital we use the average emission intensity of a coal energy plant, which is estimated to be 0.888 tonnes $\mathrm{CO}_{2} / \mathrm{MWh}$, while for a gas plant those estimates average at 0.499 tonnes $\mathrm{CO}_{2} / \mathrm{MWh}$, as reported by WNA (2011). Salvadore and Keppler (2010) reported an investment cost between 9-18 USD/MWh at a $5 \%$ discount rate, while at a $10 \%$ discount rate the investment costs range between 17.5 and $30 \mathrm{USD} / \mathrm{MWh}$. Therefore, at a $5 \%$ discount rate we get an emission intensity of $5 \%-10 \%$ per unit of capital invested in a coal plant, while at a $10 \%$ discount rate, the emission intensity ranges from $3 \%$ to $6 \%$. For a gas plant, investment costs range between 5.5-9 USD/MWh at 5\% discount rate, and therefore, the emission intensity ranges between $5 \%-9 \%$ of each unit of capital invested in a gas plant.

Damage from global pollution stock is likely to be a persistent problem for a long time, and small values, between 1\% (Stern (2007)) and 4\% (Nordhaus (2014)), are usually used for the time discount rate $\rho$. However, in order to be consistent with the calibration of other parameters we use $\rho$ between $5 \%-10 \%$. This does not greatly affect the results obtained.

The investment cost parameter $\beta_{b}$ represents the rate of increase of the marginal investment cost in brown capital per unit of investment. We use values of $\beta_{b}$ ranging between $2 \%$ and $8 \%$.

Depending on the estimated life time for a wind energy plant (around 40 years), we use the same depreciation rate for both types of capital, resulting in a range for $\delta$ between $2.5 \%-5 \%$.

Higher values of the parameters $\eta$ and $\eta^{n}$ imply that governments care more about the environmental quality of their consumers when taking decisions. We choose different values of these parameters to test different assumptions about the weight of environmental quality between North and South.

Annual carbon emissions from burning fossil fuels in the United States are about 1.6 gigatons (billion metric tons), whereas annual uptake is only about 0.5 gigatons, resulting in a net release of about 1.1 gigatons per year. This implies that only $31 \%$ of the U.S carbon emissions are absorbed naturally (Sundquist et al. 2008). Using this, and an estimated emission rate between $5 \%$ and $9 \%$ of installed capital at a $5 \%$ discount rate, we arrive at a natural absorption rate of installed capital between $1.55 \%$ and $2.8 \%$ at a $5 \%$ discount rate. The resulting benchmark values for parameters can be found in Appendix C.

\section{Results}

For the analysis of the growth dynamics, we set low initial values for brown and green capital as well for the pollution stock, as we are interested in the situation that South initially falls in the 'least developed' class of countries. 


\subsection{North's allocation of aid}

We start the analysis with investigating the aid allocation of North in equilibrium, and how it is affected by parameter changes.

We know from the steady state analysis that North will give aid in steady state either if its output is sufficiently high, or if it values environmental quality highly enough. On the other hand, we have found that if South cares a lot, that is, if $\eta$ is sufficiently large, then there will be no incentive for North to give aid indefinitely, as South will make sufficient green investments on its own accord. The benchmark parametrisation describes an intermediate situation where South cares, but North has still an incentive to give aid.

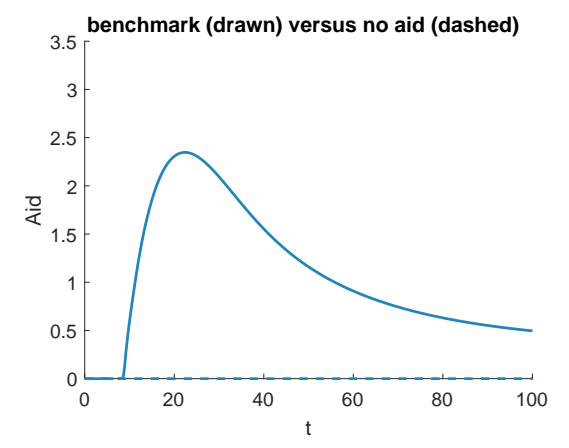

Figure 1: Aid profile over time (benchmark)

Figure 1 shows the benchmark aid profile over time. There is an initial time interval where no aid is given: this is when South's stocks of brown capital and global pollution are still at low levels. It is only when South's brown capital stock is sufficiently large that North starts giving aid. Although most of the aid is consumed, a part of it enables South to invest in green capital and thereby to lessen its emissions. North's decision to give aid is motivated only by environmental reasons - there is no 'warm glow' term in its utility function - and therefore it should be considered as mitigation aid. Whenever $\eta>0$, South cares about pollution from brown capital and has an incentive to invest relatively less in brown capital if income is higher (i.e. environmental quality is a normal good, so that demand for environmental quality rises with income). The hump shaped aid profile follows from the profile of South's brown investments, and thus emissions, in South. These correspond to an Environmental Kuznets curve: countries at a low development level tend to increase their emission until average income reaches a certain point over the course of their development.

Figures 2 and 3 show changes in the aid profile with respect to changes to different parameters, compared to the benchmark profile. In these figures, a dashed curve represents the benchmark aid profile, while the solid curve indicates the aid profile after the change. In all cases, the parameter has been increased or decreased by $20 \%$ with respect to its benchmark value. 


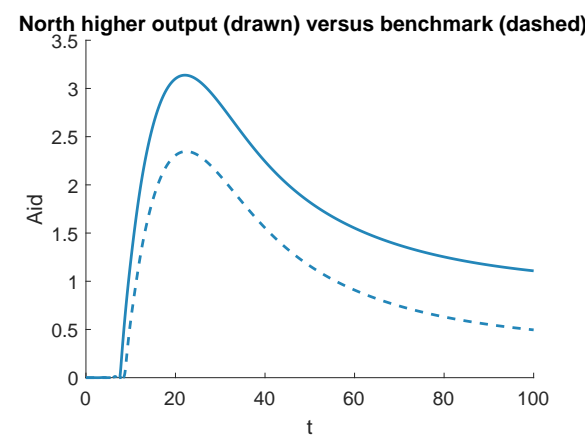

(a) Increasing North's output $Y^{n}$

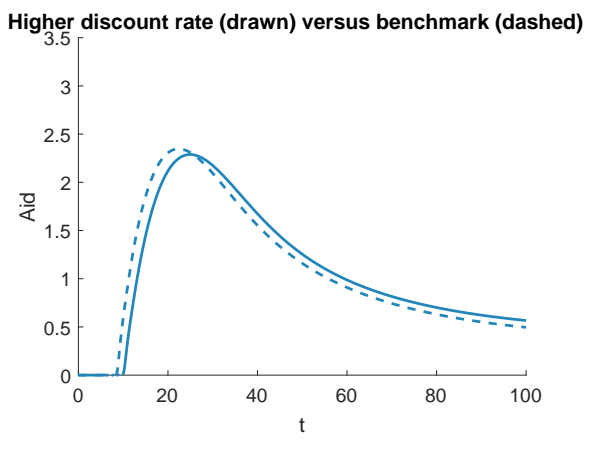

(b) Increasing time discount rate $\rho$

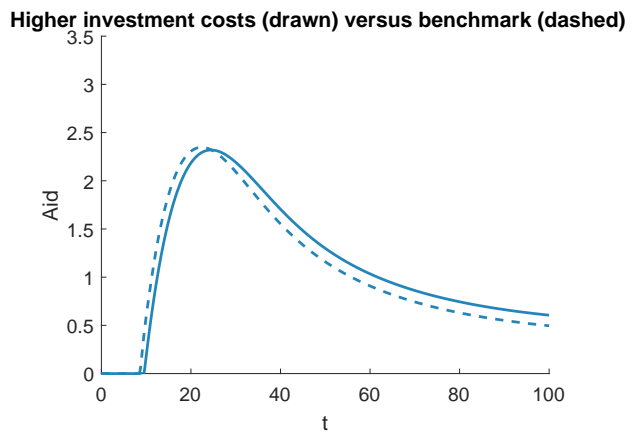

(d) Increasing both $\beta_{b}$ and $\beta_{g}$ while keeping $\beta_{g} / \beta_{b}$ constant

Figure 2: Influence of capital-related parameter changes on the aid profile

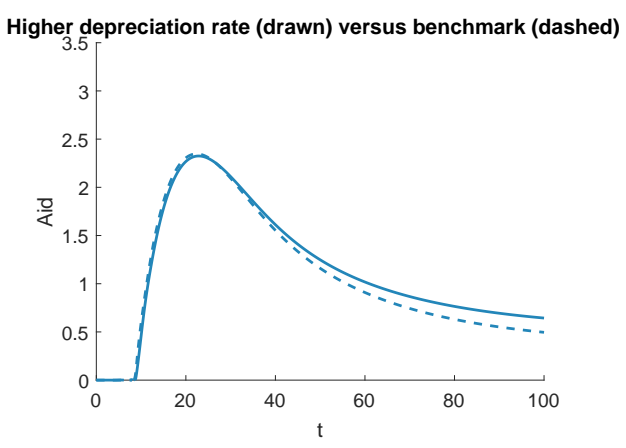

(c) Increasing depreciation rate $\delta$

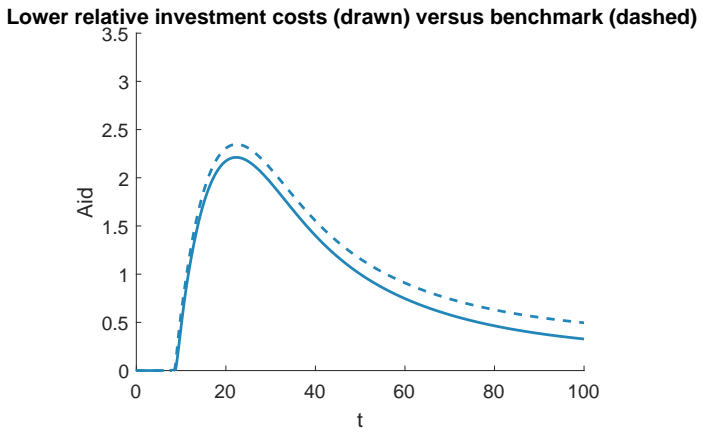

(e) Decreasing $\beta_{g}$ while keeping $\beta_{b}$ constant 


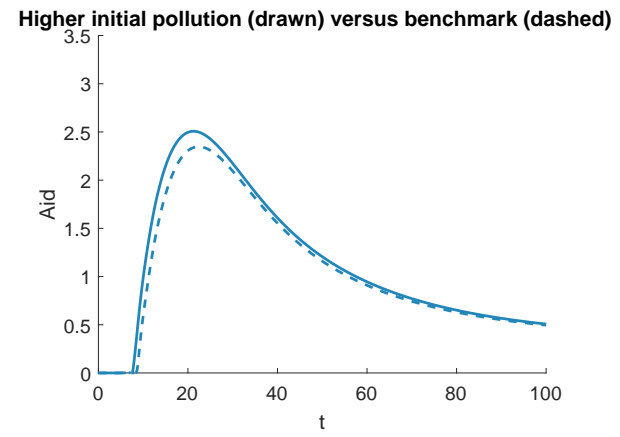

(a) Increasing initial pollution $E_{0}$

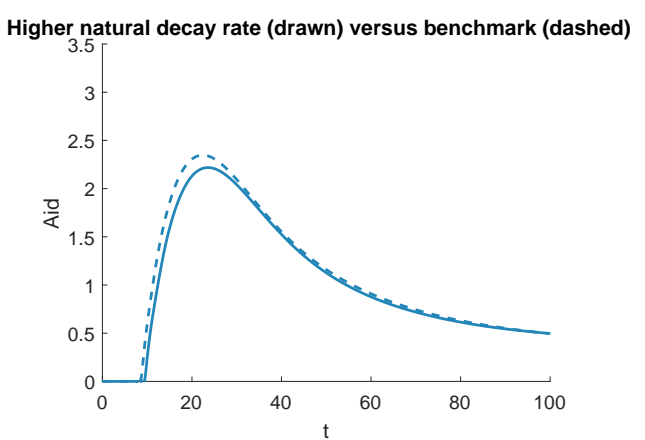

(c) Increasing natural decay rate $\vartheta$

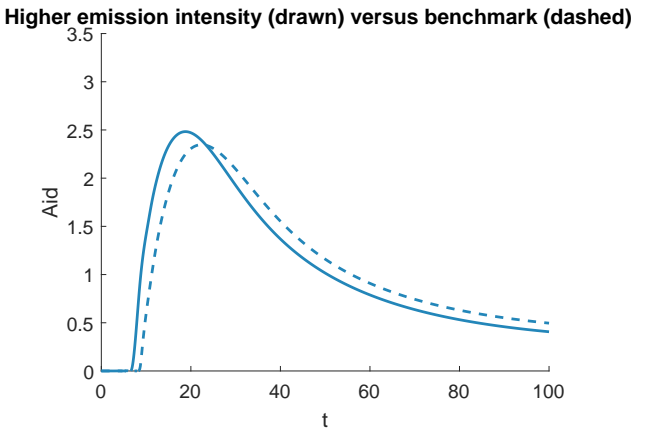

(b) Increasing emission intensity $\alpha$

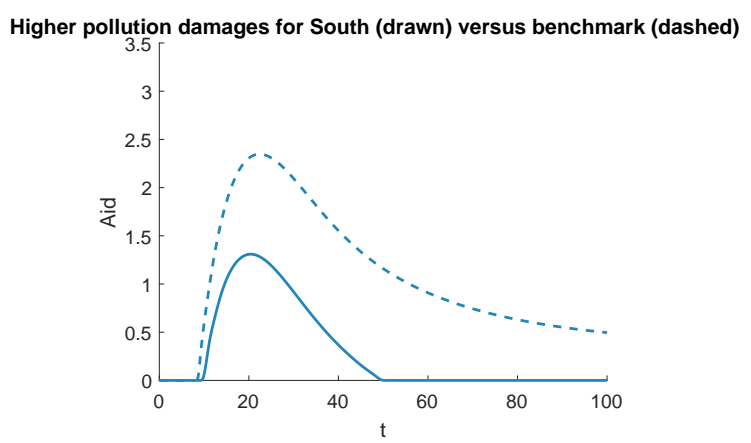

(d) Increasing South's weight of environmental quality $\eta$

Figure 3: Influence of environmental parameter changes on the aid profile 


\subsubsection{Effects of changing capital parameters}

Figure 2 illustrates the effects of changing parameters that affect the industrial output of North or South. Figure 2a shows the effect of increasing North's output: the level of aid is higher. This finding is in line with the result of Theorem 5 on steady state aid.

Figure $2 \mathrm{~b}$ increases the discount rate, which both decreases aid and shifts the aid profile to the future, because the long term effects of environmental pollution impact North's welfare less. Increasing the depreciation rate $\delta$, as in Figure 2c, has a similar but smaller effect, although the explanation is different: if capital depreciates quickly, brown capital is less quickly at a critical level. Moreover, it is inefficient to start enabling South too early to invest in green capital.

Higher values of the rate of increase in the marginal cost of investments $\beta_{g}$ and $\beta_{b}$, while keeping their ratio constant, imply again that South needs more time to build up capital towards critical levels, implying a shift of the aid profile into the future, as seen in Figure $2 \mathrm{~d}$.

If the cost $\beta_{g} / \beta_{b}$ of green investments relative to brown investments falls, aid goes down, for South is less constrained when building up its green capital.

\subsubsection{Effects of changing environmental parameters}

Figure 3 documents the consequences of changes to environmental parameters. The first panel, Figure 3a, shows the effect of an increase in the initial pollution stock: this aggravates the environmental conditions and leads North to start giving more aid more quickly, as already a smaller stock of green capital build by South improves the situation.

Higher emission intensity of brown capital makes the aid programme start sooner, Figure 3b: as brown capital emits more pollution, more damages from pollution are realised sooner by North.

If the natural decay rate of pollution increases, Figure 3c, the pollution stock decreases faster and South's emissions take longer to reach critical levels. Together this makes the problem less urgent for North, whose aid programme is reduced.

Finally, Figure 3d shows that if South's consumers put more weight on environmental quality, its incentive to build green capital increases, which in turn lowers North's incentive to give aid dramatically.

\subsection{South's use of the aid}

We turn to South consumption and investment decisions. First we analyse these as function of the model parameters. Then we study the how South allocates the aid it receives from North between consumption and total investments, and how it allocates investment aid between brown and green investments. 


\subsubsection{Aid increases consumption and green growth}

Transboundary pollution is considered as a natural asset necessary for development and for economic growth. Keeping global pollution under tolerable levels, such as keeping the average global temperature below 2 degrees, is necessary to achieve sustainable growth, and thus green growth. Therefore, in this study we measure green growth in the long run by a decrease in global pollution levels. In the short run, investing in non-polluting capital means that these investments are not taking place in the polluting sector, and therefore, lower transitional pollution and higher green growth.

The decisions of South how to allocate aid show how efficiently aid promotes economic growth of the recipient country as well as the effect of aid on the direction of growth.

In order to identify the choice of South for both decision processes, we compare the time paths of South's controls when it receives aid to those when it does not, holding all parameters constant.

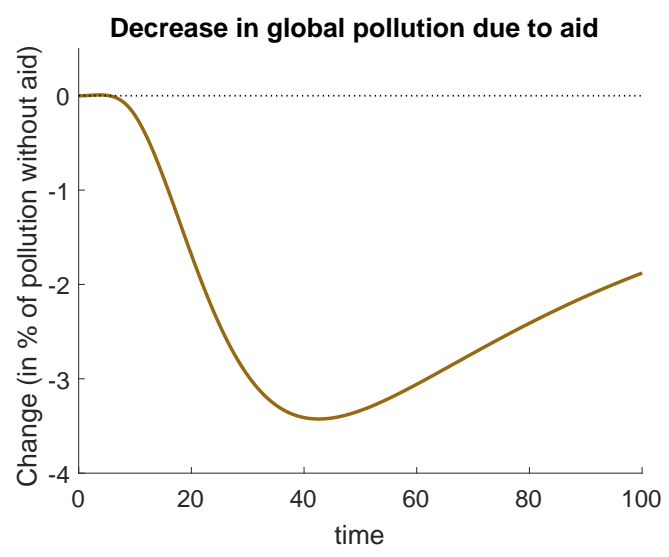

Figure 4: Effect of aid on global pollution

As mentioned in Section 6.1, in the benchmark situation North starts giving aid when the environmental conditions become critical from its perspective. Figure 4 shows the relative change of global pollution level from the benchmark without aid. Giving aid decreases the pollution stock, mainly by shifting brown capital levels downwards. The latter effect become clearer when we study the effect of aid on brown investments.

Figure 5a depicts the relative increase of South's consumption when receiving aid compared to the situation where no aid is received; Figure $5 \mathrm{~b}$ gives the corresponding increase in total investments.

The figures show that it is optimal for South to use most of the aid to smooth out its consumption schedule. This is clear from panel $5 \mathrm{a}$ as investments are postponed, consumption increases a little before aid is received. However, as South starts receiving aid, the rise in consumption takes a hump shaped similar to that of the aid profile. This seem at first sight to agree to the findings of Boone (1996), who concludes that aid primarily goes to consumption and that there is no relationship between aid and growth. Figure 5b depicts how South's total investments change over time with aid: it shows 


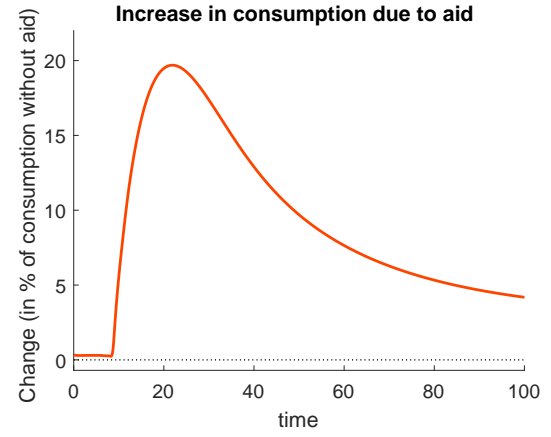

(a) Effect of aid on consumption

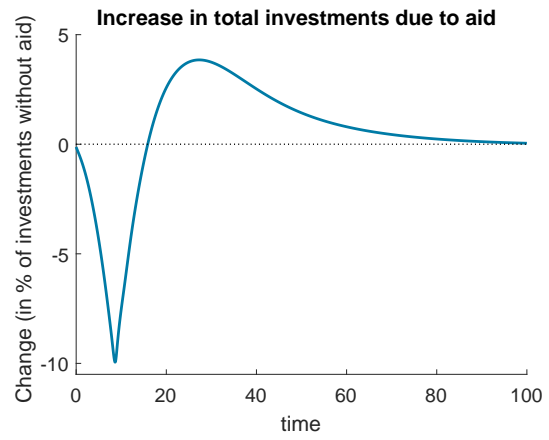

(b) Effect of aid on investments

Figure 5: South's allocation of aid between consumption and investments

that investments fall steadily relative to the situation where no aid is expected, until the moment aid starts to arrive. Investments increase again and are then for a substantial period of time over the no-aid levels. Therefore we argue that the conclusion of Boone (1996) about the relationship between aid and growth is imprecise: in our situation, aid has a positive effect on growth, but this is modest and lower than what the Harrod and Domar model would predict. These findings are in line with Chatterjee et al. (2003) who find that a temporary pure transfer has only modest short-run growth effects compared to a transfer tied to investment in public infrastructure. We note that a second effect of aid is to push investments into the future.

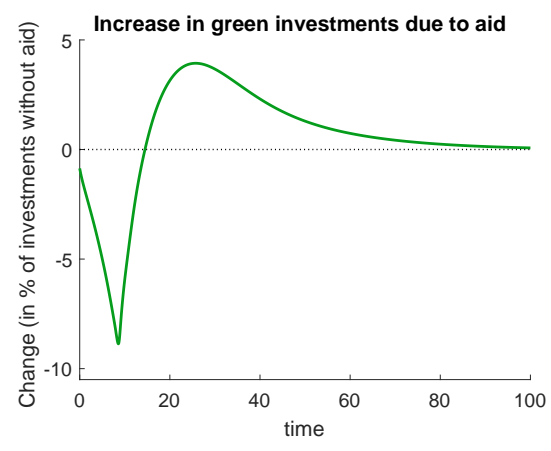

(a) Effect of aid on green investments

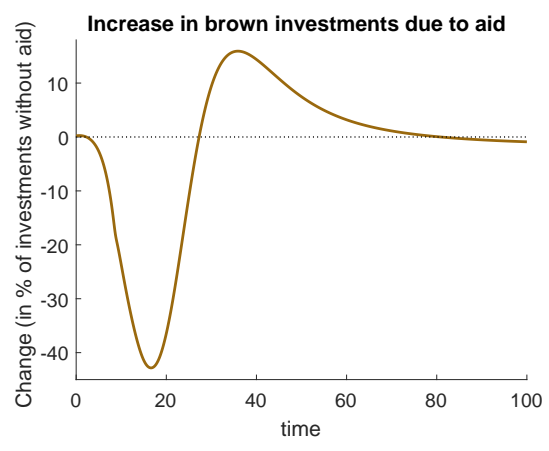

(b) Effect of aid on brown investments

Figure 6: South's allocation of aid between brown and green investments

Figure 6 depicts the change of South's investment schedule due to aid for, respectively, brown and green capital. There is a decrease of investments before the aid period begins. The maximal decrease of green investments with respect to the case that no aid is received tops out at about $8.8 \%$, before it starts to increase again and ends up at its highest about $4 \%$ higher than in the no-aid situation. Investments in brown capital fall much more strongly, to a minimum of $43 \%$ of investments in the no-aid regime. Also here we see that later on, investments in brown capital pick up again, topping out at an increase of $16 \%$ over the no-aid levels. Note however that these effects are small in absolute terms, as the 
brown capital level is much lower than the green capital levels. Moreover, since pollution stock is proportional to South's brown capital, figure 4 illustrates that aid is effective in lessening brown capital.

We summarise these findings by noting that aid has two effects on investments: it modestly increases total eventual growth, in the benchmark situation mainly for green capital, and it pushes growth farther into the future, by enabling South to increase consumption earlier.

\subsection{Time consistency}

The Stackelberg equilibria we have investigated so far are open-loop equilibria: that is, at time $t=0$ North announces an aid schedule $a_{t}$, and South subsequently makes its plans taking this schedule for granted. At any given point in time, North may reconsider its decision, which then can result in a change in the announced aid policy.

To model South's reaction to such a policy change, we extend the original differential game by introducing a binary state variable, trust, which can take the values 0 and 1 . At the beginning of the game, trust is assumed to take the value 1, which is interpreted as South trusting North to stick to its announced aid schedule. When, at some time $t>0$, North deviates from the announced schedule - this can be observed by South - trust switches from 1 to 0 , and South falls back to that growth policy which is optimal if it will receive no aid from North. North will then switch to giving no aid at all, as in the "no trust' regime giving aid will not alter South's behaviour. This is analogous to the trigger strategy mechanism in repeated games.

In order to find out whether North will stick to its original aid schedule, we have to compare, for each time $t>0$, North's payoff over the time interval $[t, \infty)$ when sticking to the announced aid schedule versus its payoff when cutting aid at time $t$. More precisely, let $\left(E_{t}, K_{b, t}, K_{g, t}\right)$ be the evolution of pollution level, brown and green capital stock, under the aid schedule $a_{t}$ announced by North at time $t=0$, and let

$$
W^{n}\left(t_{0}\right)=\int_{t_{0}}^{\infty} \mathrm{e}^{-\rho\left(s-t_{0}\right)}\left(u^{n}\left(Y^{n}-a_{s}\right)-D^{n}\left(E_{s}\right)\right) \mathrm{d} s
$$

the corresponding present value of North's welfare at time $t_{0}$. If North changes its aid payment at time $t_{0}$, South falls back to its optimal growth policy starting at time $t_{0}$, with initial values $\left(E_{t_{0}}, K_{b, t_{0}}, K_{g, t_{0}}\right)$, under the assumption that it will receive no aid. This results, amongst other things, in a different evolution $E_{t}^{0}$ of the pollution stock and a different present value

$$
W^{n, 0}\left(t_{0}\right)=\int_{t_{0}}^{\infty} \mathrm{e}^{-\rho\left(s-t_{0}\right)}\left(u^{n}\left(Y^{n}\right)-D^{n}\left(E_{s}^{0}\right)\right) \mathrm{d} s
$$

of North's welfare. If the difference

$$
\Delta_{t}=W^{n}(t)-W^{n, 0}(t)
$$


is negative for some $t>0$, North has an incentive to reconsider its aid policy at that date, and the announced policy is not time-consistent.

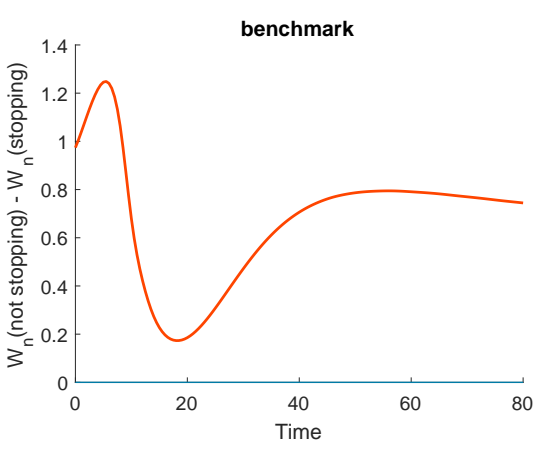

(a) Benchmark: time consistent

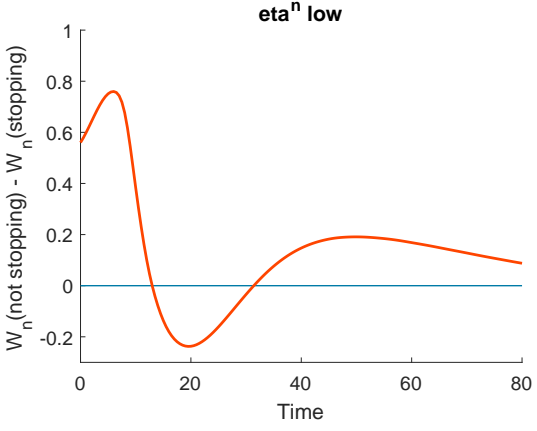

(b) Lower $\eta^{n}$ : not time consistent

Figure 7: Time consistency of the Stackelberg equilibrium

Panel 7a shows the evolution of $\Delta_{t}$ for the benchmark parametrisation. In Section 6.2 we saw that in anticipation of the aid transfers, South reduces production, resulting in lower emissions which benefits North. We conclude that in the benchmark parametrisation, giving aid is a time-consistent policy.

Panel 7b illustrates a contrasting situation: if North is less sensitive to pollution damages than in the benchmark parametrisation, giving aid is not time-consistent. Unlike the benchmark parametrisation, here aid is given only temporarily and there is no aid in steady state. Moreover, the panel shows that this quantity starts taking negative values at the moment where North should be starting making aid payments. In the benchmark situation, the long term gains in pollution reduction in steady state are always more important to North than the short time savings by not sticking to the announced aid transfers.

Accordingly, we conclude that giving unconditional aid in the open loop Stackelberg equilibrium is weakly time consistent if $\eta^{n}$ is sufficiently high.

\subsection{Main effects of giving aid}

The discussion in the previous section highlights some of the effects of aid on South's decision over time. We distinguish three effects: the first one is that South chooses to postpone a small amount of its investments until it starts receiving aid, increasing consumption instead. This is coherent with the life-cycle theory of consumption. However, the intertemporal substitution of consumption is effectively small as South is poor initially.

The second effect is that South consumes most of the aid received. This squares with much anecdotal evidence of development aid 'leaking away'. The present analysis shows however that apart from corruption and mismanagement, which undoubtedly play a role 
in practice and which are not addressed by our model, there is also the purely economic motivation that the aid is simply better employed elsewhere from South's point of view.

Thirdly, South stops developing its brown capital when receiving aid. Effectively, giving aid results in a reduction in global emissions.

\section{Conclusion}

This study identifies the dynamic effects of unconditional aid on the growth and the direction of the growth of a recipient country. We studied a differential Stackelberg game between a leading donor country and a following recipient country. The decision of the donor to give aid in our model is motivated by environmental concerns, and should be classified as mitigation aid.

We find that aid conditionality is counterproductive if the conditionality restriction is binding tightly, and only may have the intended effect in a small window of cases, which decreases to zero with the time preference rate.

Our model shows that the donor has an incentive to give aid if sufficiently rich or sufficiently concerned about the environment. This is even the case if the recipient is not at all concerned about environmental quality.

In particular, since we argue that most 'conditional' aid is in practice given virtually unconditionally, our study provides an explanation for the empirical evidence that indicates the relative ineffectiveness of aid on growth of the recipient country: our model indicates that it is optimal for the recipient to consume most of the aid and only to allocate a minor part to investments. Still, even giving unconditional aid can be a Pareto-improvement over giving no aid at all.

Our model also shows that unconditional development aid has a modest positive short term effect on growth. This effect seems however much lower than what the Harrod and Domar model predicts. At least for our benchmark case we investigated, we found that most of the increase of growth caused by aid takes place in the green sector.

A possible extensions to our model is to include demographical changes in the recipient country by adding labour as a second input for production. This would help to complete the analysis, to study whether high population growth rate in these countries necessitates a higher growth rate to meet the demographical changes: the possible effect would be that aid is more effectively used to increase growth.

As a policy recommendation, results analysed in this study suggest that as aid conditionality is counterproductive, donors should give aid unconditionally and focus on strengthening institutions in the recipient country in order that the recipient allocates the aid optimally. 


\section{Acknowledgements}

The first author acknowledges financial support by the European Commission in the framework of the European Doctorate in Economics Erasmus Mundus (EDEEM).

The authors would like to express their gratitude for valuable feedback, comments, and remarks on earlier versions of this paper to Antoine d'Autume, Herbert Dawid, Cees Diks, Katheline Schubert, Gilles Lafforgue, Sjak Smulders, Cees Withagen, Snorre Kverndokk, and an anonymous referee, as well as the participants of the following meetings, at which the paper was presented: CeNDEF Seminar, University of Amsterdam, 13 April 2015; $13^{\text {th }}$ Viennese Workshop on Optimal Control and Dynamic Games, 15 May 2015; $10^{\text {th }}$ BiGSEM Doctoral Workshop on Economic Theory, 8 December 2015; Séminaire: Economie de lÉnvironnement, Paris School of Economics, 24 March 2016; EUREKA Seminar, VU University, 28 April 2016; SURED, 7 June 2016; $22^{\text {nd }}$ Annual Conference of the European Association of Environmental and Resource Economists, 24 June 2016.

\section{References}

Adam, C. S. and O'Connell, S. A. (1999). Aid, taxation and development in sub-saharan africa. Economics and Politics, 11(3):225-253.

Alesina, A. and Dollar, D. (2000). Who gives foreign aid to whom and why? Journal of Economic Growth, 5(1):33-63.

Altemeyer-Bartscher, M., Rübbelke, D. T., and Sheshinski, E. (2010). Environmental protection and the private provision of international public goods. Economica, 77(308):775-784.

Azam, J.-P. and Laffont, J.-J. (2003). Contracting for aid. Journal of Development Economics, $70(1): 25-58$.

Baldwin, E., Cai, Y., and Kuralbayeva, K. (2016). Build Today, Regret Tomorrow? Infrastructure and Climate Policy. Working paper.

Boone, P. (1996). Politics and the effectiveness of foreign aid. European Economic Review, 40(2):289-329.

Bowen, A., Cochrane, S., and Fankhauser, S. (2012). Climate change, adaptation and economic growth. Climatic Change, 113(2):95-106.

Buchholz, W. and Konrad, K. A. (1995). Strategic transfers and private provision of public goods. Journal of Public Economics, 57(3):489-505.

Chatterjee, S., Sakoulis, G., and Turnovsky, S. J. (2003). Unilateral capital transfers, public investment, and economic growth. European Economic Review, 47(6):1077-1103.

Claude, D., Figuières, C., and Tidball, M. (2012). Regulation of investments in infrastructure: The interplay between strategic behaviors and initial endowments. Journal of Public Economic Theory, 14(1):35-66. 
Doucouliagos, H. and Paldam, M. (2008). Aid effectiveness on growth: a meta study. European Journal of Political Economy, 24(1):1-24.

Easterly, W. (2003). Can foreign aid buy growth? Journal of Economic Perspectives, 17(3):2348.

Eyckmans, J., Fankhauser, S., and Kverndokk, S. (2016). Development aid and climate finance. Environmental and resource economics, 63(2):429-450.

Eyraud, L., Zhang, C., Wane, A. A., and Clements, B. J. (2011). Who's Going Green and Why? Trends and Determinants of Green Investment. IMF Working Papers 11/296, International Monetary Fund.

Grass, D. (2012). Numerical computation of the optimal vector field: Exemplified by a fishery model. Journal of Economic Dynamics and Control, 36(10):1626-1658.

Hansen, H. and Tarp, F. (2000). Aid effectiveness disputed. Journal of International Development, 12(3):375-398.

Heuson, C., Peters, W., Schwarze, R., and Topp, A.-K. (2015). Voluntary international climate finance under the post-Kyoto framework: The strategic consequences of different modes of funding. Climate Change Economics, 6(03):1550013.

Ihori, T. (1996). International public goods and contribution productivity differentials. Journal of Public Economics, 61(1):139-154.

Klein, R. J., Schipper, E. L. F., and Dessai, S. (2005). Integrating mitigation and adaptation into climate and development policy: three research questions. Environmental science $\&$ policy, 8(6):579-588.

Lahiri, S. and Raimondos-Moller, P. (2000). Lobbying by ethnic groups and aid allocation. Economic Journal, 110(462):C62-79.

Mekasha, T. J. and Tarp, F. (2013). Aid and growth: What meta-analysis reveals. Journal of Development Studies, 49(4):564-583.

Morath, F. (2010). Strategic information acquisition and the mitigation of global warming. Journal of Environmental Economics and Management, 59(2):206-217.

Mosley, P. (1986). Aid-effectiveness: The micro-macro paradox. IDS Bulletin, 17(2):22-27.

Mosley, P., Harrigan, J., and Toye, J. F. (1995). Aid and power: the World Bank and policy-based lending. Psychology Press.

Nordhaus, W. D. (2014). A question of balance: Weighing the options on global warming policies. Yale University Press.

Ono, T. (1998). Consumption externalities and the effects of international income transfers on the global environment. Journal of Economics, 68(3):255-269.

Ono, T. and Maeda, Y. (2002). On the index of environmental awareness. Environmental economics and policy studies, 5(2):167-178. 
Pittel, K. and Rübbelke, D. T. (2013). Improving global public goods supply through conditional transfers-the international adaptation transfer riddle. Working paper series, CESifo.

Rajan, R. G. and Subramanian, A. (2008). Aid and growth: What does the cross-country evidence really show? The Review of Economics and Statistics, 90(4):643-665.

Rosenstein-Rodan, P. N. (1961). International aid for underdeveloped countries. The Review of Economics and Statistics, 43(2):107-138.

Rozenberg, J., Vogt-Schilb, A., and Hallegatte, S. (2014). Transition to clean capital, irreversible investment and stranded assets. Policy Research Working Paper Series 6859, The World Bank.

Rübbelke, D. T. (2011). International support of climate change policies in developing countries: Strategic, moral and fairness aspects. Ecological Economics, 70(8):1470-1480.

Salvadore, M. S. and Keppler, J. H. (2010). Projected costs of generating electricity: 2010 edition. Technical report, Paris Dauphine University.

Stern, N. H. (2007). The economics of climate change: the Stern review. cambridge University press.

Stranlund, J. K. (1996). On the strategic potential of technological aid in international environmental relations. Journal of Economics, 64(1):1-22.

Sundquist, E., Burruss, R., Faulkner, S., Gleason, R., Harden, J., Kharaka, Y., Tieszen, L., and Waldrop, M. (2008). Carbon sequestration to mitigate climate change. Technical report, US Geological Survey.

Svensson, J. (2000). When is foreign aid policy credible? Aid dependence and conditionality. Journal of Development Economics, 61(1):61-84.

Svensson, J. (2003). Why conditional aid does not work and what can be done about it? Journal of Development Economics, 70(2):381-402.

Vicary, S. and Sandler, T. (2002). Weakest-link public goods: Giving in-kind or transferring money. European Economic Review, 46(8):1501-1520.

Warr, P. G. (1983). The private provision of a public good is independent of the distribution of income. Economics letters, 13(2-3):207-211.

WNA (2011). Comparison of life cycle ghg emissions of various electricity generation sources. Technical report, World Nuclear Association.

\section{A South}

\section{A.1 South's decision problem}

The current value Lagrangian of South's intertemporal maximisation problem is

$$
L=u\left(c_{t}\right)-D\left(E_{t}\right)+\mu_{t}\left(\alpha K_{b, t}-\vartheta E_{t}\right)+\nu_{b, t}\left(I_{b, t}-\delta K_{b, t}\right)+\nu_{g, t}\left(I_{g, t}-\delta K_{g, t}\right)
$$




$$
+\Lambda_{t}\left(F\left(K_{b, t}, K_{g, t}\right)+a_{t}-C_{b}\left(I_{b, t}\right)-C_{g}\left(I_{g, t}\right)-c_{t}\right)+\zeta_{t}\left(C_{g}\left(I_{g, t}\right)-\varepsilon a_{t}\right) .
$$

Here $\mu_{t}, \nu_{b, t}, \nu_{g_{t}}$ and $\Lambda_{t}$ are the shadow valuations of, respectively, the pollution stock, South's brown capital, South's green capital and South's consumption; $\zeta_{t}$ is the multiplier of the conditionality restriction. The first order necessary conditions for an optimum yield

$$
0=\nu_{b, t}-\Lambda_{t} C_{b}^{\prime}\left(I_{b, t}\right), \quad 0=\nu_{g, t}-\left(\Lambda_{t}-\zeta_{t}\right) C_{g}^{\prime}\left(I_{g, t}\right), \quad 0=u^{\prime}\left(c_{t}\right)-\Lambda_{t},
$$

which determine the optimal actions $I_{b, t}, I_{g, t}$ and $c_{t}$, and

$$
\begin{aligned}
\dot{\mu}_{t} & =D^{\prime}\left(E_{t}\right)+(\rho+\vartheta) \mu_{t}, \\
\dot{\nu}_{b, t} & =-\Lambda_{t} F_{K_{b}}^{\prime}\left(K_{b, t}, K_{g, t}\right)+(\rho+\delta) \nu_{b, t}-\alpha \mu_{t}, \\
\dot{\nu}_{g, t} & =-\Lambda_{t} F_{K_{g}}^{\prime}\left(K_{b, t}, K_{g, t}\right)+(\rho+\delta) \nu_{g, t},
\end{aligned}
$$

which determine the shadow valuations. These conditions are complemented by the budget equation

$$
0=F\left(K_{b, t}, K_{g, t}\right)+a_{t}-C_{b}\left(I_{b, t}\right)-C_{g}\left(I_{g, t}\right)-c_{t},
$$

the complementary slackness condition

$$
\zeta_{t}\left(C_{g}\left(I_{g, t}\right)-\varepsilon a_{t}\right)=0
$$

the non-negativity condition $\zeta_{t} \geq 0$, initial conditions for the states $E_{t}, K_{b, t}$ and $K_{g, t}$ and, since there are no terminal conditions on the states, by the transversality conditions

$$
\lim _{t \rightarrow \infty} e^{-\rho t} E_{t}=0, \quad \lim _{t \rightarrow \infty} e^{-\rho t} K_{i, t}=0, \quad i \in\{b, g\},
$$

which hold whenever the state variables are uniformly bounded away from 0 .

\section{A.2 South's steady state}

Here, we compute and analyse the steady state of South's decision problem under the assumption that the aid schedule $a_{t}=a$ is constant in time. To denote a steady state value of a dynamic quantity, we drop the subscript $t$.

\section{A.3 Green capital}

First, we derive the steady state level of green capital. At steady state, we obtain from the capital evolution equation (7) the steady state condition

$$
I_{i}=\delta K_{i}, \quad \text { for } \quad i \in\{b, g\} .
$$


Equation (26) determining South's marginal valuation $\nu_{g, t}$ of green capital $K_{g, t}$ yields the steady state condition

$$
(\rho+\delta) \nu_{g}=u^{\prime}(c) F_{K_{g}}^{\prime}\left(K_{b}, K_{g}\right)
$$

Equation (23) implies at steady state

$$
\nu_{g}=C_{g}^{\prime}\left(I_{g}\right)\left(u^{\prime}(c)-\zeta\right)
$$

Finally, we have the restriction $C_{g}\left(I_{g}\right) \geq \varepsilon a$ and the associated complementary slackness condition

$$
\zeta\left(C_{g}\left(I_{g}\right)-\varepsilon a\right)=0 .
$$

We use (32) to eliminate $\nu_{g}$ from (31), to obtain

$$
u^{\prime}(c) F_{K_{g}}^{\prime}\left(K_{b}, K_{g}\right)=(\rho+\delta) C_{g}^{\prime}\left(I_{g}\right)\left(u^{\prime}(c)-\zeta\right)
$$

First consider the situation that the green investment restriction is not binding. Then $\zeta=0$ and we can divide out $u^{\prime}(c)$ from both sides of (34). Using (30) to eliminate $I_{g}$ yields then

$$
F_{K_{g}}^{\prime}\left(K_{b}, K_{g}\right)=(\rho+\delta) C_{g}^{\prime}\left(\delta K_{g}\right)
$$

equating marginal productivity to marginal discounted investment costs.

If the production function is separable (3), then the equation simplifies to

$$
F_{g}^{\prime}\left(K_{g}\right)=(\rho+\delta) C_{g}^{\prime}\left(\delta K_{g}\right)
$$

This equation determines the steady state level $K_{g}$ of green capital as a function of the system's parameters; $K_{g}$ in turn determines the steady state level $I_{g}$ of green investments. Note in particular that in this situation green capital and green investments at steady state do not depend on aid.

If on the other hand the green investment restriction is binding, then

$$
I_{g}=C_{g}^{-1}(\varepsilon a) \quad \text { and } \quad K_{g}=\frac{C_{g}^{-1}(\varepsilon a)}{\delta}
$$

while

$$
\zeta=u^{\prime}(c)\left(1-\frac{F_{K_{g}}^{\prime}\left(K_{b}, K_{g}\right)}{(\rho+\delta) C_{g}^{\prime}\left(I_{g}\right)}\right)
$$

In this case, the steady state levels of investment and green capital depend directly on the amount of aid given. 


\section{A.4 Brown capital}

We turn to brown capital. From the budget constraint (5), we write steady state consumption $c$ as a function of aid $a$ and brown capital $K_{b}$

$$
c=F\left(K_{b}, K_{g}\right)+a-C_{b}\left(\delta K_{b}\right)-C_{g}\left(\delta K_{g}\right) .
$$

From (8) and (24) it follows that

$$
E=\frac{\alpha}{\vartheta} K_{b}
$$

and

$$
\mu=-\frac{D^{\prime}(E)}{(\rho+\vartheta)}=-\frac{D^{\prime}\left(\frac{\alpha}{\vartheta} K_{b}\right)}{(\rho+\vartheta)} .
$$

This yields $E$ and $\mu$ as functions of $K_{b}$.

Eliminating $\mu$ from (25) using (41), both at steady state, yields

$$
(\rho+\delta) \nu_{b}=u^{\prime}(c) F_{K_{b}}^{\prime}\left(K_{b}, K_{g}\right)-\frac{\alpha}{\rho+\vartheta} D^{\prime}\left(\frac{\alpha}{\vartheta} K_{b}\right) .
$$

Using (23) and (30), we obtain a second expression

$$
\nu_{b}=u^{\prime}(c) C_{b}^{\prime}\left(\delta K_{b}\right)
$$

for $\nu_{b}$. After eliminating $\nu_{b}$ from (42), we finally obtain

$$
F_{K_{b}}^{\prime}\left(K_{b}, K_{g}\right)=(\rho+\delta) C_{b}^{\prime}\left(\delta K_{b}\right)+\frac{\alpha}{(\rho+\vartheta)} \frac{D^{\prime}\left(\frac{\alpha}{\vartheta} K_{b}\right)}{u^{\prime}(c)},
$$

equating marginal productivity gains to the sum of marginal discounted investment costs and marginal environmental damage costs. Note that the environmental damage term depends inversely on the marginal utility of consumption, and, all other things constant, will increase with the consumption level, and hence with aid.

If the production function is separable (3), this relation simplifies to

$$
F_{b}^{\prime}\left(K_{b}\right)=(\rho+\delta) C_{b}^{\prime}\left(\delta K_{b}\right)+\frac{\alpha}{(\rho+\vartheta)} \frac{D^{\prime}\left(\frac{\alpha}{\vartheta} K_{b}\right)}{u^{\prime}(c)},
$$

We see from this relation that even in the separable case, the steady state brown capital level $K_{b}$ is sensitive to aid, that is, to changes in $c$. 


\section{A.5 Proofs of theorem $2-4$}

\section{A.5.1 Proof of theorem 2}

It follows from (36) that aid does not affect the steady state level of green capital, and hence that $\frac{\partial K_{g}}{\partial a}=0$. Consumption $c$ and brown capital $K_{b}$ are jointly determined by (14) and (15), which can be written as

$$
\begin{aligned}
& G_{1}=c+C_{b}\left(\delta K_{b}\right)+C_{g}\left(\delta K_{g}\right)-F\left(K_{b}, K_{g}\right)-a=0, \\
& G_{2}=(\rho+\delta) C_{b}^{\prime}\left(\delta K_{b}\right)-F_{K_{b}}^{\prime}\left(K_{b}, K_{g}\right)+\frac{\alpha}{(\rho+\vartheta)} \frac{D^{\prime}\left(\frac{\alpha}{\vartheta} K_{b}\right)}{u^{\prime}(c)}=0 .
\end{aligned}
$$

Introduce the vector-valued functions $G=\left(G_{1}, G_{2}\right)$, whose components are net expenses and net marginal productivity costs, the variable $X=\left(c, K_{b}\right)$, and introduce the derivative

$$
D_{X} G=\left(\begin{array}{ll}
\frac{\partial G_{1}}{\partial c} & \frac{\partial G_{1}}{\partial K_{b}} \\
\frac{\partial G_{2}}{\partial c} & \frac{\partial G_{2}}{\partial K_{b}}
\end{array}\right) .
$$

We shall need the elements of the matrix $D_{X} G$ and its inverse. These are

$$
\begin{array}{ll}
\frac{\partial G_{1}}{\partial c}=1, & \frac{\partial G_{1}}{\partial K_{b}}=\delta C_{b}^{\prime}-F_{K_{b}}^{\prime}, \\
\frac{\partial G_{2}}{\partial c}=\frac{\alpha}{\rho+\vartheta} D^{\prime} \frac{\left(-u^{\prime \prime}\right)}{\left(u^{\prime}\right)^{2}}, & \frac{\partial G_{2}}{\partial K_{b}}=(\rho+\delta) \delta C_{b}^{\prime \prime}-F_{K_{b} K_{b}}^{\prime \prime}+\frac{\alpha^{2}}{(\rho+\vartheta) \vartheta} \frac{D^{\prime \prime}}{u^{\prime}} .
\end{array}
$$

It follows from the assumptions of $F_{b}, u$ and $D$ that $\frac{\partial G_{1}}{\partial c}>0, \frac{\partial G_{2}}{\partial c}>0$ and $\frac{\partial G_{2}}{\partial K_{b}}>0$. Using (43) to eliminate $F_{K_{b}}^{\prime}$, we find that

$$
\frac{\partial G_{1}}{\partial K_{b}}=\delta C_{b}^{\prime}-F_{K_{b}}^{\prime}=-\rho C_{b}^{\prime}-\frac{\alpha}{(\rho+\vartheta)} \frac{D^{\prime}}{u^{\prime}}<0 .
$$

This implies that the determinant $\Delta=\operatorname{det} D_{X} G$ is positive. Setting

$$
-\left(D_{X} G\right)^{-1}=B=\left(\begin{array}{ll}
B_{11} & B_{12} \\
B_{21} & B_{22}
\end{array}\right)
$$

these results imply that $B_{11}<0, B_{12}<0$ and $B_{22}<0$, while $B_{21}>0$.

Since

$$
D_{a} X=-\left(D_{X} G\right)^{-1} D_{a} G
$$

we also have to compute the elements of $D_{a} G$, which evaluate to $\frac{\partial G_{1}}{\partial a}=-1$ and $\frac{\partial G_{2}}{\partial a}=0$. Equation (45) then implies that $\frac{\partial c}{\partial a}=-B_{11}>0$ and $\frac{\partial K_{b}}{\partial a}=-B_{21}<0$. This shows the results about consumption and dirty and green capital. The results about investments and the pollution stock follow from equations (30) and (40). If consumption increases and the pollution stock decreases, South's welfare increases. 


\section{A.5.2 Proof of theorem 3}

Retaining the notations from the previous proof, we note that

$$
\left(\begin{array}{c}
\frac{\partial c}{\partial \beta_{i}} \\
\frac{\partial K_{b}}{\partial \beta_{i}}
\end{array}\right)=B D_{\beta_{i}} G=B\left(\begin{array}{c}
\frac{\partial G_{1}}{\partial \beta_{i}} \\
\frac{\partial G_{2}}{\partial \beta_{i}}
\end{array}\right) \quad \text { for } \quad i \in\{b, g\} .
$$

For green investment costs, we have

$$
\frac{\partial G_{1}}{\partial \beta_{g}}=\frac{\delta^{2}}{2} K_{g}^{2}>0, \quad \frac{\partial G_{2}}{\partial \beta_{g}}=0,
$$

hence

$$
\frac{\partial c}{\partial \beta_{g}}=B_{11} \frac{\delta^{2}}{2} K_{g}^{2}<0, \quad \frac{\partial K_{b}}{\partial \beta_{g}}=B_{21} \frac{\delta^{2}}{2} K_{g}^{2}>0 .
$$

Then, for brown investment costs

$$
\frac{\partial G_{1}}{\partial \beta_{b}}=\frac{\delta^{2}}{2} K_{b}^{2}>0, \quad \frac{\partial G_{2}}{\partial \beta_{b}}=(\rho+\delta) \delta K_{b}>0
$$

which implies

$$
\frac{\partial c}{\partial \beta_{b}}=B_{11} \frac{\delta^{2}}{2} K_{b}^{2}+B_{21}(\rho+\delta) \delta K_{b}<0
$$

and

$$
\frac{\partial K_{b}}{\partial \beta_{b}}=B_{21} \frac{\delta^{2}}{2} K_{g}^{2}+B_{22}(\rho+\delta) \delta K_{b}
$$

In the last expression, the two terms on the right hand side have opposite signs. However, if the emission intensity $\alpha=0$, then $B_{21}=0$ and

$$
\left.\frac{\partial K_{b}}{\partial \beta_{b}}\right|_{\alpha=0}<0
$$

which implies, by continuity, that $\frac{\partial K_{b}}{\partial \beta_{b}}<0$ for values of $\alpha$ close to 0 .

Finally, for the capital depreciation rate

$$
\frac{\partial G_{1}}{\partial \delta}=\beta_{g} \delta K_{g}^{2}+\beta_{b} \delta K_{b}^{2}>0, \quad \frac{\partial G_{2}}{\partial \delta}=(\rho+2 \delta) \beta_{b} K_{b}>0 .
$$

Analogously to the situation of brown investment costs, this implies

$$
\frac{\partial c}{\partial \delta}<0
$$

whereas the sign of $\frac{\partial K_{b}}{\partial \delta}$ is undetermined in general, but for $\alpha$ taking values close to 0 , we 
have that $\frac{\partial K_{b}}{\partial \delta}<0$.

\section{A.5.3 Proof of theorem 4}

Again retaining the notations of the proof of theorem 2, and using $E=\frac{\alpha}{\vartheta} K_{b}$, we find

$$
\begin{aligned}
D_{\vartheta} G & =-\left(\frac{\alpha}{(\rho+\vartheta)^{2}} \frac{D^{\prime}(E)}{u^{\prime}(c)}+\frac{\alpha}{\rho+\vartheta} \frac{D^{\prime \prime}(E)}{u^{\prime}(c)} E\right)\left(\begin{array}{l}
0 \\
1
\end{array}\right) \\
& =-\frac{\alpha}{(\rho+\vartheta)^{2}} \frac{D^{\prime}(E)}{u^{\prime}(c)}\left(1+(\rho+\vartheta) \frac{E D^{\prime \prime}(E)}{D^{\prime}(E)}\right)\left(\begin{array}{l}
0 \\
1
\end{array}\right)=-C\left(\begin{array}{l}
0 \\
1
\end{array}\right),
\end{aligned}
$$

where $C>0$ : that is, net expenses are not affected by changes in the natural decay rate, but net marginal productivity costs decrease if $\vartheta$ increases. It follows that

$$
\frac{\partial c}{\partial \vartheta}=-B_{12} C>0, \quad \frac{\partial K_{b}}{\partial \vartheta}=-B_{22} C>0
$$

From

$$
D_{\alpha} G=\frac{1}{\rho+\vartheta} \frac{D^{\prime}(E)}{u^{\prime}(c)}\left(1+\frac{E D^{\prime \prime}(E)}{D^{\prime}(E)}\right)\left(\begin{array}{l}
0 \\
1
\end{array}\right),
$$

the factor in brackets being positive, it follows in the same manner that $\frac{\partial c}{\partial \alpha}<0, \frac{\partial K_{b}}{\partial \alpha}<0$. Using the functional form $D(E)=\eta E^{2} / 2$, we find

$$
D_{\eta} G=\left(\frac{\alpha}{\rho+\vartheta} \frac{\frac{\alpha}{\vartheta} K_{b}}{u^{\prime}(c)}\right)\left(\begin{array}{l}
0 \\
1
\end{array}\right) .
$$

In the same manner as before, we obtain $\frac{\partial c}{\partial \eta}<0, \frac{\partial K_{b}}{\partial \eta}<0$.

\section{B North}

\section{B.1 North's decision problem}

The current value Lagrangian associated to the maximisation of North's social welfare is then

$$
\begin{aligned}
L^{n}= & u^{n}\left(Y^{n}-a_{t}\right)-D^{n}\left(E_{t}\right) \\
& +\kappa_{b, t}\left(\frac{\nu_{b, t}}{\beta_{b} u^{\prime}\left(c_{t}\right)}-\delta K_{b, t}\right)+\kappa_{g, t}\left(\frac{\nu_{g, t}}{\beta_{g} u^{\prime}\left(c_{t}\right)}-\delta K_{g, t}\right)+\psi_{t}\left(\alpha K_{b, t}-\vartheta E_{t}\right) \\
& +\lambda_{b, t}\left((\rho+\delta) \nu_{b, t}-u^{\prime}\left(c_{t}\right) F_{b}^{\prime}\left(K_{b, t}\right)-\alpha \mu_{t}\right) \\
& +\lambda_{g, t}\left((\rho+\delta) \nu_{g, t}-u^{\prime}\left(c_{t}\right) F_{g}^{\prime}\left(K_{g, t}\right)\right)+\tau_{t}\left((\rho+\vartheta) \mu_{t}+D^{\prime}\left(E_{t}\right)\right)
\end{aligned}
$$




$$
+\Lambda_{t}^{n}\left(F_{b}\left(K_{b, t}\right)+F_{g}\left(K_{g, t}\right)+a_{t}-\frac{\nu_{b, t}^{2}}{2 \beta_{b} u^{\prime}\left(c_{t}\right)^{2}}-\frac{\nu_{g, t}^{2}}{2 \beta_{g} u^{\prime}\left(c_{t}\right)^{2}}-c_{t}\right)+\xi_{t} a_{t} .
$$

The variables $\kappa_{b, t}, \kappa_{g, t}$ and $\psi_{t}$ are North's shadow valuations of South's brown capital, green capital, and global pollution respectively, whereas $\lambda_{b, t}, \lambda_{g, t}$ and $\tau_{t}$ are North's shadow valuations of South's shadow valuations of brown capital, green capital and the pollution stock. The Lagrange multipliers associated to South's budget constraint and to the aid positivity constraint are denoted $\Lambda_{t}^{n}$ and $\xi_{t}$ respectively.

The first order necessary conditions yield

$$
\begin{aligned}
0= & -u^{\prime \prime}\left(c_{t}\right)\left(\lambda_{b, t} F_{b}^{\prime}\left(K_{b, t}\right)+\lambda_{g, t} F_{g}^{\prime}\left(K_{g, t}\right)+\frac{1}{u^{\prime}\left(c_{t}\right)^{2}}\left(\frac{\kappa_{b, t} \nu_{b, t}}{\beta_{b}}+\frac{\kappa_{g, t} \nu_{g, t}}{\beta_{g}}\right)\right) \\
& +\Lambda_{t}^{n}\left(\frac{u^{\prime \prime}\left(c_{t}\right)}{u^{\prime}\left(c_{t}\right)^{3}}\left(\frac{\nu_{b, t}^{2}}{\beta_{b}}+\frac{\nu_{g, t}^{2}}{\beta_{g}}\right)-1\right), \\
0= & \xi_{t}-\left(u^{n}\right)^{\prime}\left(Y^{n}-a_{t}\right)+\Lambda_{t}^{n},
\end{aligned}
$$

which determine the optimal actions $a_{t}$ and $c_{t}$ : note that in the Stackelberg problem, South's consumption is an action of North. North's shadow valuations are determined by

$$
\begin{aligned}
\dot{\kappa}_{b, t} & =(\rho+\delta) \kappa_{b, t}+\lambda_{b, t} u^{\prime}\left(c_{t}\right) F_{b}^{\prime \prime}\left(K_{b, t}\right)-\Lambda_{t}^{n} F_{b}^{\prime}\left(K_{b, t}\right)-\alpha \psi_{t} \\
\dot{\kappa}_{g, t} & =(\rho+\delta) \kappa_{g, t}+\lambda_{g, t} u^{\prime}\left(c_{t}\right) F_{g}^{\prime \prime}\left(K_{g, t}\right)-\Lambda_{t}^{n} F_{g}^{\prime}\left(K_{g, t}\right) \\
\dot{\psi}_{t} & =(\rho+\vartheta) \psi_{t}+\left(D^{n}\right)^{\prime}\left(E_{t}\right)-\tau_{t} D^{\prime \prime}\left(E_{t}\right) \\
\dot{\lambda}_{b, t} & =-\delta \lambda_{b, t}-\frac{\kappa_{b, t}}{\beta_{b} u^{\prime}\left(c_{t}\right)}+\Lambda_{t}^{n} \frac{\nu_{b, t}}{\beta_{b} u^{\prime}\left(c_{t}\right)^{2}} \\
\dot{\lambda}_{g, t} & =-\delta \lambda_{g, t}-\frac{\kappa_{g, t}}{\beta_{g} u^{\prime}\left(c_{t}\right)}+\Lambda_{t}^{n} \frac{\nu_{g, t}}{\beta_{g} u^{\prime}\left(c_{t}\right)^{2}} \\
\dot{\tau}_{t} & =-\vartheta \tau_{t}+\alpha \lambda_{b, t} .
\end{aligned}
$$

These equations are complemented by the complementary slackness condition

$$
0=\xi_{t} a_{t}
$$

and the non-negativity constraint $\xi_{t} \geq 0$.

Finally, there are initial and terminal conditions. We already have the initial conditions for the states $E_{t}, K_{b, t}$ and $K_{g, t}$ and the terminal conditions (29) on the co-states of South's problem. Moreover, both South's states and South's co-states are states of North's problem. Since there is no terminal condition on South's states and no initial condition on South's co-states, there will be a terminal transversality condition on North's co-states of South's states, that is, on $\kappa_{i, t}$ and $\psi_{t}$, and an initial transversality condition on North's co-states of South's co-states, that is, on $\lambda_{i, t}$ and $\tau_{t}$. These conditions read as

$$
\lim _{t \rightarrow \infty} e^{-\rho t} \psi_{t}=0, \quad \lim _{t \rightarrow \infty} e^{-\rho t} \kappa_{b, t}=0, \quad \lim _{t \rightarrow \infty} e^{-\rho t} \kappa_{g, t}=0,
$$


again assuming that the corresponding states are uniformly bounded away from 0 , and

$$
\lambda_{b, 0}=0, \quad \lambda_{g, 0}=0, \quad \tau_{0}=0 .
$$

\section{B.2 North's aid decision}

This section proves theorem 5 by demonstrating the validity of equation (21).

In the analysis of South's steady state, aid $a$ was treated as an external parameter. From the steady state conditions of North's co-state equations, we derive an equation that links North's steady state aid level to South's consumption level $c$ and South's brown capital level $K_{b}$.

The equation

$$
\xi=\left(u^{n}\right)^{\prime}\left(Y^{n}-a\right)-\Lambda^{n}
$$

shows that $\xi$ are North's net marginal shadow costs of giving aid, while $\Lambda^{n}$ are North's marginal shadow benefits of increasing South's budget; as long as $\xi>0$, North cannot increase its welfare by giving aid.

Note that if $a=0$, then $\Lambda^{n}$ is independent of $\xi$ and the restriction $\xi \geq 0$ together with equation (58) implies an upper bound $\bar{Y}^{n}$ for $Y^{n}$, which satisfies $\left(u^{n}\right)^{\prime}\left(\bar{Y}^{n}\right)=\Lambda^{n}$. Conversely, if $Y^{n}>\bar{Y}^{n}$, then necessarily $\xi=0, a>0$ and it is optimal for North to give aid. This proves the first statement in the theorem if $\Lambda^{n}>0$.

We turn to the sign of North's shadow valuations of South's capital in steady state. We first solve the $\lambda_{i}$ from the steady state versions of (52) and (53), to obtain

$$
\lambda_{i}=\frac{\nu_{i} \Lambda^{n}-\kappa_{i} u^{\prime}}{\delta \beta_{i}\left(u^{\prime}\right)^{2}}
$$

Equations (23), together with (30) provide

$$
\nu_{i}=\delta \beta_{i} K_{i} u^{\prime}
$$

We solve for $\tau$, North's shadow valuation of South's shadow valuations of the pollution stock, and $\psi$, North's shadow valuation of the pollution stock, as

$$
\tau=\frac{\alpha}{\vartheta} \frac{\nu_{b} \Lambda^{n}-\kappa_{b} u^{\prime}}{\delta \beta_{b}\left(u^{\prime}\right)^{2}}
$$

and

$$
\psi=\frac{1}{\rho+\vartheta}\left(\frac{\alpha}{\vartheta} \frac{\nu_{b} \Lambda^{n}-\kappa_{b} u^{\prime}}{\delta \beta_{b}\left(u^{\prime}\right)^{2}} D^{\prime \prime}-\left(D^{n}\right)^{\prime}\right) .
$$


This yields equations for North's shadow valuations of South's capital stocks

$$
\begin{aligned}
& 0=(\rho+\delta) \kappa_{g}+\frac{\nu_{g} \Lambda^{n}-\kappa_{g} u^{\prime}}{\delta \beta_{g} u^{\prime}} F_{g}^{\prime \prime}-\Lambda^{n} F_{g}^{\prime} \\
& 0=(\rho+\delta) \kappa_{b}+\frac{\nu_{b} \Lambda^{n}-\kappa_{b} u^{\prime}}{\delta \beta_{g} u^{\prime}} F_{b}^{\prime \prime}-\Lambda^{n} F_{b}^{\prime}-\frac{\alpha}{\rho+\vartheta}\left(\frac{\alpha}{\vartheta} \frac{\nu_{b} \Lambda^{n}-\kappa_{b} u^{\prime}}{\delta \beta_{b}\left(u^{\prime}\right)^{2}} D^{\prime \prime}-\left(D^{n}\right)^{\prime}\right) .
\end{aligned}
$$

Rearranging yields

$$
\begin{aligned}
\left(\rho+\delta-\frac{F_{g}^{\prime \prime}}{\delta \beta_{g}}\right) \kappa_{g}= & \Lambda^{n}\left(F_{g}^{\prime}-K_{g} F_{g}^{\prime \prime}\right) \\
\left(\rho+\delta-\frac{F_{b}^{\prime \prime}}{\delta \beta_{b}}+\frac{\alpha^{2}}{(\rho+\vartheta) \vartheta \delta \beta_{b}} \frac{D^{\prime \prime}}{u^{\prime}}\right) \kappa_{b}=- & \frac{\alpha}{\rho+\vartheta}\left(D^{n}\right)^{\prime} \\
& +\Lambda^{n}\left(F_{b}^{\prime}-K_{b} F_{b}^{\prime \prime}+\frac{\alpha^{2}}{(\rho+\vartheta) \vartheta} \frac{D^{\prime \prime}}{u^{\prime}} K_{b}\right)
\end{aligned}
$$

Equation (61) is simplified by using (36) to

$$
\left(\rho+\delta-\frac{F_{g}^{\prime \prime}}{\delta \beta_{g}}\right) \kappa_{g}=\Lambda^{n}\left((\rho+\delta) \beta_{g} \delta K_{g}-K_{g} F_{g}^{\prime \prime}\right)=\Lambda^{n} \beta_{g} \delta K_{g}\left(\rho+\delta-\frac{F_{g}^{\prime \prime}}{\delta \beta_{g}}\right)
$$

whence we conclude that

$$
\kappa_{g}=\Lambda^{n} \beta_{g} \delta K_{g}
$$

Taking our cue from this solution, we attempt to find $\kappa_{b}$ in the form $\kappa_{b}=\delta \beta_{b}\left(\Lambda^{n} K_{b}+X\right)$. Substituting this expression into (62) yields

$$
\begin{aligned}
& \left((\rho+\delta) \delta \beta_{b}-F_{b}^{\prime \prime}+\frac{\alpha^{2}}{(\rho+\vartheta) \vartheta} \frac{D^{\prime \prime}}{u^{\prime}}\right)\left(\Lambda^{n} K_{b}+X\right) \\
& =-\frac{\alpha}{\rho+\vartheta}\left(D^{n}\right)^{\prime}+\Lambda^{n}\left(F_{b}^{\prime}-K_{b} F_{b}^{\prime \prime}+\frac{\alpha^{2}}{(\rho+\vartheta) \vartheta} \frac{D^{\prime \prime}}{u^{\prime}} K_{b}\right)
\end{aligned}
$$

This can be rewritten as

$$
\left((\rho+\delta) \delta \beta_{b}-F_{b}^{\prime \prime}+\frac{\alpha^{2}}{(\rho+\vartheta) \vartheta} \frac{D^{\prime \prime}}{u^{\prime}}\right) X=-\frac{\alpha}{\rho+\vartheta}\left(D^{n}\right)^{\prime}+\Lambda^{n}\left(F_{b}^{\prime}-(\rho+\delta) \delta \beta_{b} K_{b}\right)
$$

The quantity $X$ is then determined by the equation

$$
\left((\rho+\delta) \delta \beta_{b}-F_{b}^{\prime \prime}+\frac{\alpha^{2}}{(\rho+\vartheta) \vartheta} \frac{D^{\prime \prime}}{u^{\prime}}\right) X=\frac{\alpha}{\rho+\vartheta}\left(-\left(D^{n}\right)^{\prime}+\Lambda^{n} \frac{D^{\prime}}{u^{\prime}}\right) .
$$

This yields

$$
\kappa_{b}=\delta \beta_{b}\left(\Lambda^{n} K_{b}+\frac{\alpha}{\rho+\vartheta} \frac{-\left(D^{n}\right)^{\prime}+\Lambda^{n} D^{\prime} / u^{\prime}}{(\rho+\delta) \delta \beta_{b}-F_{b}^{\prime \prime}+\frac{\alpha^{2}}{(\rho+\vartheta) \vartheta} \frac{D^{\prime \prime}}{u^{\prime}}}\right) .
$$


Finally, we compute $\Lambda^{n}$, which satisfies

$$
\Lambda^{n}\left(\frac{1}{\left(u^{\prime}\right)^{2}}\left(\frac{\nu_{b}^{2}}{\beta_{b}}+\frac{\nu_{g}^{2}}{\beta_{g}}\right)+\frac{u^{\prime}}{\left(-u^{\prime \prime}\right)}\right)=u^{\prime}\left(\lambda_{b} F_{b}^{\prime}+\lambda_{g} F_{g}^{\prime}\right)+\frac{\kappa_{b} \nu_{b}}{\beta_{b} u^{\prime}}+\frac{\kappa_{g} \nu_{g}}{\beta_{g} u^{\prime}} .
$$

The right hand side of this equation is

$$
\begin{aligned}
& u^{\prime}\left(\lambda_{b} F_{b}^{\prime}+\lambda_{g} F_{g}^{\prime}\right)+\frac{\kappa_{b} \nu_{b}}{\beta_{b} u^{\prime}}+\frac{\kappa_{g} \nu_{g}}{\beta_{g} u^{\prime}} \\
& =u^{\prime}\left(\frac{\nu_{b} \Lambda^{n}-\kappa_{b} u^{\prime}}{\delta \beta_{b}\left(u^{\prime}\right)^{2}} F_{b}^{\prime}+\frac{\nu_{g} \Lambda^{n}-\kappa_{g} u^{\prime}}{\delta \beta_{g}\left(u^{\prime}\right)^{2}} F_{g}^{\prime}\right)+\frac{\kappa_{b} \nu_{b}}{\beta_{b} u^{\prime}}+\frac{\kappa_{g} \nu_{g}}{\beta_{g} u^{\prime}} \\
& =\frac{\Lambda^{n}}{u^{\prime}}\left(\frac{\nu_{b} F_{b}^{\prime}}{\delta \beta_{b}}+\frac{\nu_{g} F_{g}^{\prime}}{\delta \beta_{g}}\right)+\frac{\kappa_{b}}{\delta \beta_{b}}\left(\delta \nu_{b} / u^{\prime}-F_{b}^{\prime}\right)+\frac{\kappa_{g}}{\delta \beta_{g}}\left(\delta \nu_{g} / u^{\prime}-F_{g}^{\prime}\right) \\
& =\Lambda^{n}\left(K_{b} F_{b}^{\prime}+K_{g} F_{g}^{\prime}\right)+\left(\delta^{2} \beta_{b} K_{b}-F_{b}^{\prime}\right)\left(\Lambda^{n} K_{b}+X\right)+\left(\delta^{2} \beta_{g} K_{g}-F_{g}^{\prime}\right) \Lambda^{n} K_{g} \\
& =\Lambda^{n}\left(\beta_{b} \delta^{2} K_{b}^{2}+\beta_{g} \delta^{2} K_{g}^{2}\right)+X\left(\delta^{2} \beta_{b} K_{b}-F_{b}^{\prime}\right) .
\end{aligned}
$$

We bring the terms involving $\Lambda^{n}$ to the left hand side of (63) and use (44) to rewrite the remaining term on the right hand side. The equation then reads as

$$
\begin{aligned}
& \Lambda^{n}\left(\frac{u^{\prime}}{\left(-u^{\prime \prime}\right)}+\frac{1}{\left(u^{\prime}\right)^{2}}\left(\frac{\nu_{b}^{2}}{\beta_{b}}+\frac{\nu_{g}^{2}}{\beta_{g}}\right)-\beta_{b} \delta^{2} K_{b}^{2}-\beta_{g} \delta^{2} K_{g}^{2}+\frac{\frac{\alpha}{\rho+\vartheta} \frac{D^{\prime}}{u^{\prime}}\left(\rho \delta \beta_{b} K_{b}+\frac{\alpha}{\rho+\vartheta} \frac{D^{\prime}}{u^{\prime}}\right)}{(\rho+\delta) \delta \beta_{b}-F_{b}^{\prime \prime}+\frac{\alpha^{2}}{(\rho+\vartheta) \vartheta} \frac{D^{\prime \prime}}{u^{\prime}}}\right) \\
& \quad=\frac{\alpha}{\rho+\vartheta} \frac{\left(D^{n}\right)^{\prime}\left(\rho \delta \beta_{b} K_{b}+\frac{\alpha}{\rho+\vartheta} \frac{D^{\prime}}{u^{\prime}}\right)}{(\rho+\delta) \delta \beta_{b}-F_{b}^{\prime \prime}+\frac{\alpha^{2}}{(\rho+\vartheta) \vartheta} \frac{D^{\prime \prime}}{u^{\prime}}} .
\end{aligned}
$$

We note finally that (60) implies that the left hand side simplifies further. We obtain the result that

$$
\Lambda^{n}=u^{\prime} \frac{\frac{\alpha}{\rho+\vartheta}\left(D^{n}\right)^{\prime}}{\frac{\alpha}{\rho+\vartheta} D^{\prime}+\frac{\left(u^{\prime}\right)^{2}}{\left(-u^{\prime \prime}\right)} \frac{(\rho+\delta) \delta \beta_{b}-F_{b}^{\prime \prime}+\frac{\alpha^{2}}{(\rho+\vartheta) \vartheta} \frac{D^{\prime \prime}}{u^{\prime}}}{\rho \delta \beta_{b} K_{b}+\frac{\alpha}{\rho+\vartheta} \frac{D^{\prime}}{u^{\prime}}}},
$$

which is clearly positive if $\alpha>0$.

This concludes the proof of theorem 5 .

\section{Benchmark parametrisation}

\begin{tabular}{|c|c|c|c|c|c|c|c|}
\hline Parameter & Value & Parameter & Value & Parameter & Value & Parameter & Value \\
\hline \hline$K_{b, 0}$ & 1 & $\delta$ & 0.025 & $\gamma$ & 0.75 & $\alpha$ & 0.05 \\
\hline$K_{g, 0}$ & 1 & $T$ & 300 & $\rho$ & 0.05 & $\vartheta$ & 0.016 \\
\hline$E_{0}$ & 15 & $\Omega$ & 0.6 & $\beta_{b}$ & 0.05 & $\eta$ & 0.0006 \\
\hline$\varepsilon$ & 0.5 & $\sigma$ & 0.5 & $\beta_{g}$ & 0.125 & $\eta^{n}$ & 0.023 \\
\hline$Y^{n}$ & 12.123 & & & & & & \\
\hline
\end{tabular}

